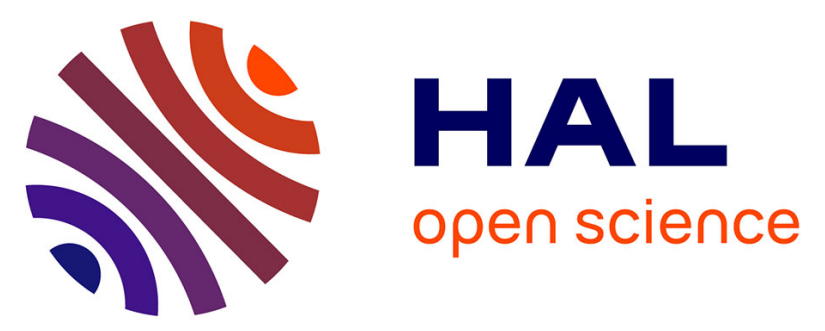

\title{
Characterization and modeling of forged Ti-6Al-4V Titanium alloy with microstructural considerations during quenching process
}

Renaud Julien, Vincent Velay, Vanessa Vidal, Yoann Dahan, Romain Forestier, Farhad Rezai-Aria

\section{To cite this version:}

Renaud Julien, Vincent Velay, Vanessa Vidal, Yoann Dahan, Romain Forestier, et al.. Characterization and modeling of forged Ti-6Al-4V Titanium alloy with microstructural considerations during quenching process. International Journal of Mechanical Sciences, 2018, 142-143, pp.456-467. 10.1016/j.ijmecsci.2018.05.023 . hal-01799489

\section{HAL Id: hal-01799489 \\ https://imt-mines-albi.hal.science/hal-01799489}

Submitted on 28 May 2018

HAL is a multi-disciplinary open access archive for the deposit and dissemination of scientific research documents, whether they are published or not. The documents may come from teaching and research institutions in France or abroad, or from public or private research centers.
L'archive ouverte pluridisciplinaire HAL, est destinée au dépôt et à la diffusion de documents scientifiques de niveau recherche, publiés ou non, émanant des établissements d'enseignement et de recherche français ou étrangers, des laboratoires publics ou privés. 


\title{
Characterization and modeling of forged Ti-6Al-4V Titanium alloy with microstructural considerations during quenching process
}

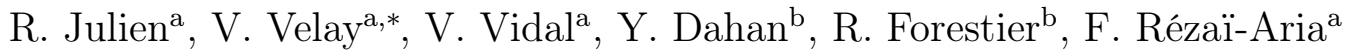 \\ ${ }^{a}$ Institut Clément Ader, Université de Toulouse; CNRS, Mines Albi, INSA, UPS, \\ ISAE-SUPAERO, Campus Jarlard, 81013 Albi Cedex 09, France \\ ${ }^{b}$ Aubert et Duval, 75 Boulevard de la Libération, BP 173, 09102 Pamiers Cedex, France
}

\begin{abstract}
The present investigation proposes an experimental device able to assess the thermomechanical behavior of Ti-6Al-4V Titanium alloy throughout the die-forging operation. Constitutive equations are developed to assess the influence of the process (die-forging temperature, cooling rate) and the microstructure parameters on the mechanical response of the alloy. For this purpose, a non-unified behavior model formulation is implemented, which defines two main mechanisms related to $\alpha$ and $\beta$ phases and allows the prediction of hardening, strain rate sensitivity and temperature, combined with the phase evolution that is dependent on the cooling conditions and which can greatly affect the mechanical behavior. This identification strategy is then applied for die-forging temperatures below the $\beta$-transus temperature, which requires microstructural information provided by SEM (Scanning Electron Microscopy) observations and image analysis. Finally, the approach is extended to die-forging temperatures above the $\beta$-transus temperature.
\end{abstract}

Keywords: Behavior modeling, Microstructural evolution, Heat treatment, Forged Titanium alloy

\section{Introduction}

Titanium alloys are widely used in the aerospace industry for their well-known high mechanical strength/weight ratio [1]. They can be used as forged semi-finished products in many industrial applications. These products are transformed into final parts by subsequent thermo-mechanical heat treatments and machining operations. Depending on the temperature of the thermo-mechanical processing (TMP) and the heat treatments (HT), various complex microstructures can be achieved. Titanium alloys can be heat-treated above or below the $\beta$-transus temperature depending upon the specific micro-structural aspects required in terms of grain size and morphology, as well as the existence of phases and mechanical strength requested by the end-users. HT generally consists in an isothermal dwell for a certain period of time

\footnotetext{
${ }^{*}$ Corresponding author

Email address: vincent.velay@mines-albi.fr (V. Velay)
} 
following quenching. To fulfil the microstructural characteristics and mechanical performance requirements and according to the size of the semi-finished products, an appropriate quenching environment (e.g., air, oil, water, etc.) is selected. The dimensions of the product and the quenching conditions can drastically influence the spatial quenching rates, specifically the time-temperature history, in any points in the product. In fact, quenching operations generate transient time-temperature histories in a part, moving inwards from the surface to the bulk. One of the major concerns, particularly for products with large dimensions, is to guarantee a homogeneous microstructure through all regions of the product. Another major technical concern is to avoid any excessive distortions during quenching and also hot tearing, which result in internal defect initiation, such as micro- and/or mesoscopic cracking. While the post-quenching surface cracking can be eliminated by subsequent machining, the undetectable internal cracking becomes a major parameter that can drastically disqualify a semi-finished product for reasons of nonconformity. Moreover, these operations induce important residual stresses in the part, which makes the final milling stage difficult. Predicting the internal residual strains/stresses has become mandatory in industrial practice. The relevant constitutive laws therefore need to be developed. However, one important problem is that during HT and quenching the microstructure and phases in titanium alloys evolve depending on the kinetics of the phase evolutions, in that they are time-temperature rate dependent. Furthermore, titanium alloys have a complex mechanical behavior, exhibiting strain rate sensitivity effects $[2,3]$, which can be reproduced through viscosity laws [4-6]. These effects becomes significant for temperatures greater than $500^{\circ} \mathrm{C}[7,8]$. Depending on the test temperature, this phenomenon can be combined with hardening effects induced by dislocation motions and resulting from a competition between storage and annihilation terms $[9,10]$. At very high temperatures, other mechanisms are induced, such as grain boundary sliding $[11,12]$. Moreover, important microstructural changes can occur, such as grain growth, or phase fraction evolutions, which themselves greatly influence the mechanical behavior, and therefore need to be introduced in the model formulation [13-15]. Indeed, these evolutions can involve strain hardening $[5,16]$ or softening due to dynamic recrystallization [17] under large deformation conditions. Moreover, when the $\beta$-phase is predominant, particular phenomena, caused by the pinning-depinning effect of the dislocation, can affect the mechanical behavior (Yield point effect). This effect was investigated at the scale of the single crystal $[18,19]$ then generalized at the scale of the polycrystal [11, 20-22]. Hence, non-unified approaches can be implemented in order to define several inelastic mechanisms associated with each phase evolution [14, 23-25]. Such approaches can translate grain-boundary strengthening caused by a lamellar microstructure [26-29].

The present study proposes a behavior model that is able to faithfully predict the strain-stress response of the material during the quenching operation. Considering all the aspects described above, a laboratory experiment testing facility has been developed to conduct in-situ heat-treatment at temperatures beyond or lower than $\beta$-transus temperature on a cylindrical specimen [30]. Then, tensile tests were combined in order to assess the behavior of the alloy under transient thermo-mechanical loadings. The microstructural evolutions are greatly influenced by the cooling rate 


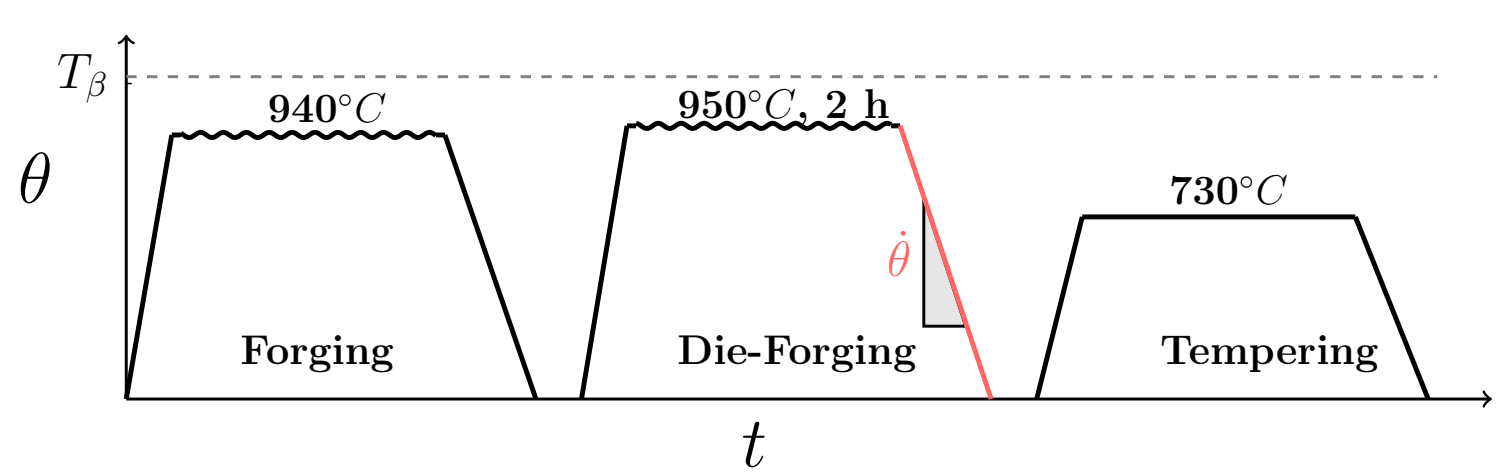

and can exhibit several phases (primary and secondary $\alpha$ phase and $\beta$ phase), the proportions of which were assessed by SEM observations and image analysis. In such complex conditions, the mechanical behavior was characterized for several temperature levels and cooling rates. From these experiments, non-unified constitutive equations were implemented to define several mechanisms related to each phase. They consider a rule of mixture between phases depending on the cooling conditions. This rule plays an important role on the activated mechanisms influencing the mechanical behavior. The model formulation can take account of the strain rate sensitivity and the hardening over a wide temperature range (from the die-forging temperature to the ambient temperature) and several cooling rates connected to various microstructural states. This behavior model was identified for die-forging temperatures below the $\beta$-transus temperature. Finally, the approach was successfully extended to die-forging temperatures above the $\beta$-transus temperature.

\section{Experimental procedures}

\subsection{Material and device}

Industrial thermo-mechanical heat treatment consists in 3 main operations, as shown in Fig. 1:

- forging at $940^{\circ} \mathrm{C}$

- die-forging at $950^{\circ} \mathrm{C}$

- tempering at $730^{\circ} \mathrm{C}$.

Figure 1: Thermo-mechanical industrial process

The material studied in the present work was supplied by Aubert \& Duval as a billet of Ti-6Al-4V Titanium alloy after the forging operation. Cylindrical specimens were machined from this billet. At this stage, an equi-axed microstructure was observed, which included $\alpha$ primary nodules, decorated at grain boundaries by the $\beta$ phase, as shown in Fig. 2a. Depending on the microstructure needs (equiaxed, duplex or lamellar morphology), the die-forging operation can be carried out at different temperatures that are higher or lower than the $\beta$-transus temperature $\left(T_{\beta}=1000^{\circ} \mathrm{C}\right)$. In the present case, the die-forging temperature considered is $950^{\circ} \mathrm{C}$ (i.e. below the $\beta$-transus temperature). During the cooling/quenching from 


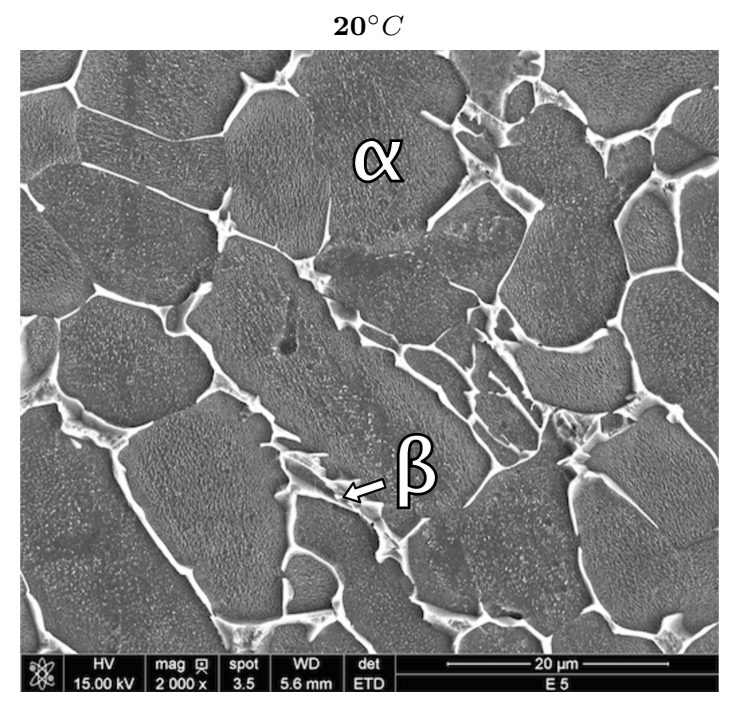

(a) this temperature, the $\beta$ phase transforms into a lamellar microstructure consisting of colonies of secondary $\alpha$ in the $\beta$ phase (labelled $\beta_{t}$ ). At this die-forging temperature, the phase transformation is not entirely completed and a duplex microstructure is obtained, regardless of the cooling conditions (Fig. $2 \mathrm{~b}$ at $60^{\circ} \mathrm{C} / \mathrm{min}$ ).

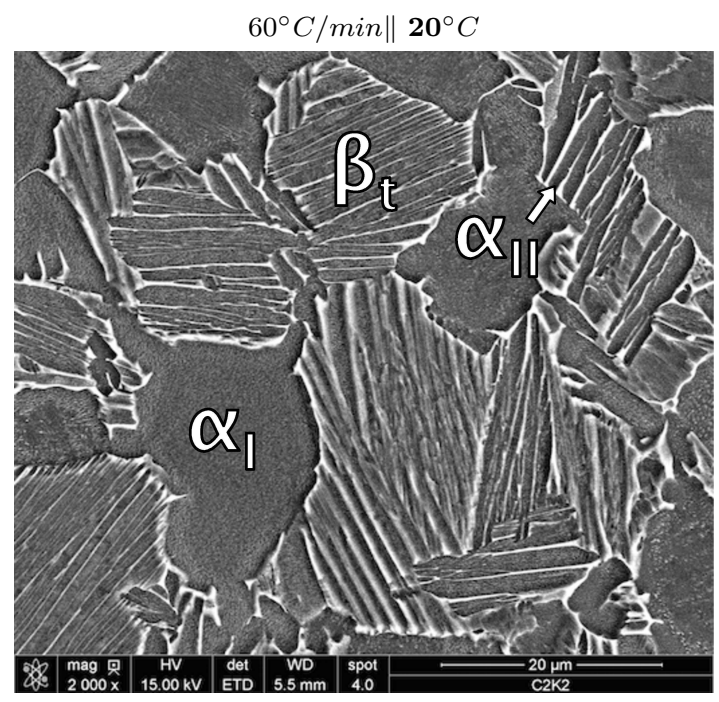

(b)

Figure 2: Starting microstructure of Ti-6Al-4V : (a) after Forging, (b) after time-temperature heat treatment corresponding to the Die-Forging (cooling rate: $60^{\circ} \mathrm{C} / \mathrm{min}$ ) [Kroll Reagent $|\mathrm{SEM}| \times$ 2000]

The cooling rate greatly influences the induced microstructure. Indeed, the thickness of the secondary (lamellar) $\alpha$-phase diminishes as the cooling rate increases. In order to characterize the mechanical behavior during the quenching operation after die-forging, an experimental device was specially developed to reproduce the industrial heat treatment. It is based on a Schenck hydropuls hydraulic tensile test machine with a nominal force up to $250 \mathrm{kN}$. It allows an in-situ heat treatment by using an induction coil, which ensures a homogeneous temperature at the center of the sample. The specimens were heated by a $2 \mathrm{~kW}$ Celes generator. A cylindrical specimen was first instrumented by 9 spot-welded thermocouples to control the longitudinal and circumferential temperature gradients. In the gauge length, thermal gradients were about $1^{\circ} \mathrm{C} / \mathrm{mm}$ and $1^{\circ} \mathrm{C} / 120^{\circ}$ angle respectively in longitudinal and circumferential directions. The strain was measured by high temperature extensometer with ceramic rods and a $10 \mathrm{~mm}$ gauge length. The system allows fast heating and cooling steps. During each test, the samples were heated up to $950^{\circ} \mathrm{C}$ with a dwell time of 2 hours at this temperature (die-forging temperature). Then the samples were cooled down to different temperatures (ranging from $950^{\circ} \mathrm{C}$ to room temperature) before starting the mechanical loading. Thus, after only a few seconds of dwell time, the tensile tests were performed in air atmosphere by maintaining the temperature constant. The tensile test consisted in a first mechanical loading with a constant strain rate and a maximal strain of $1 \%$, followed by a tensile dwell time of $10 \mathrm{~min}$ and a second loading to reach a total strain of $2 \%$. At the end of the mechanical test, air spraying was applied at the surface of the sample to prevent 
an evolution of the microstructure (mainly the growth of the phases). A schematic view of the tests performed is shown in Fig. 3.

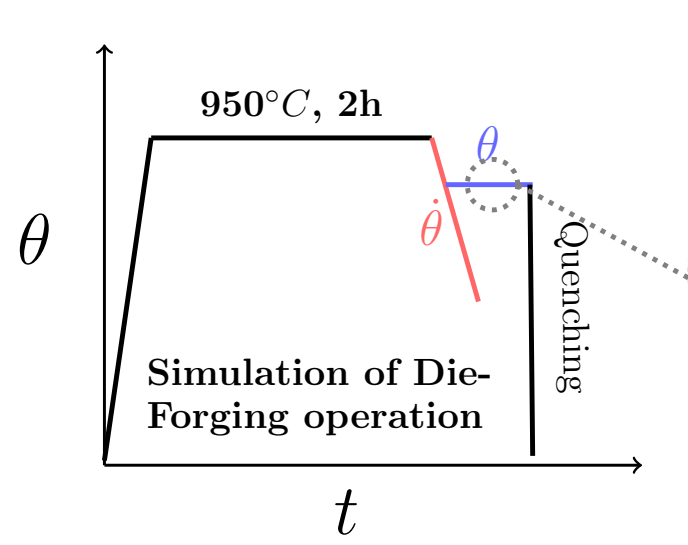

(a)

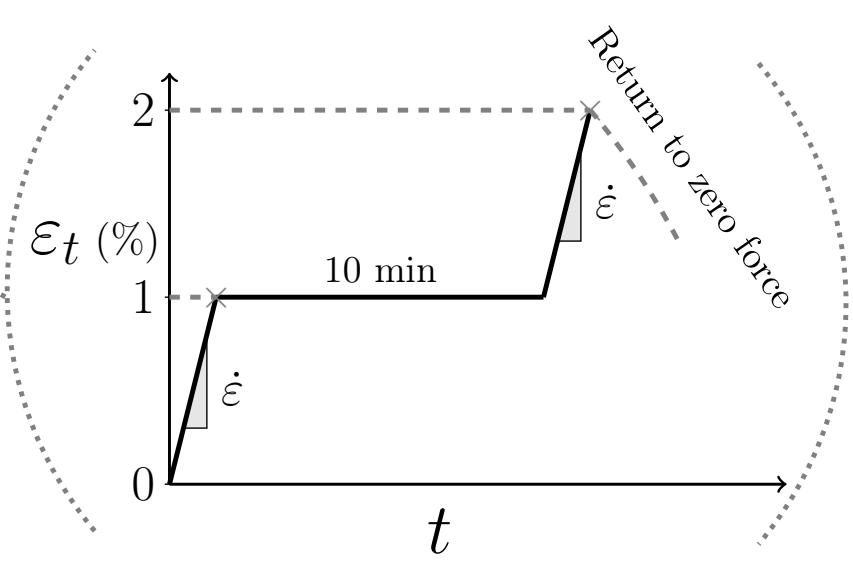

(b)

Figure 3: Test procedure (a) In-situ heat treatment; (b) Isothermal loading path

\subsection{Tensile tests}

The test conditions (see Fig. 3) were selected in order to accurately reproduce the thermo-mechanical loadings induced in the billet during the die-forging step. This analysis led to three cooling conditions being considered $\left(\dot{\theta}=\{5,60,200\}^{\circ} \mathrm{C} / \mathrm{min}\right)$ and several strain rates $\left(10^{-4} s^{-1} \leq \dot{\varepsilon} \leq 10^{-2} s^{-1}\right)$. Moreover, three temperature domains were investigated:

- from $950^{\circ} \mathrm{C}$ to $800^{\circ} \mathrm{C}$

- from $800^{\circ} \mathrm{C}$ to $500^{\circ} \mathrm{C}$

- from $500^{\circ} \mathrm{C}$ to $20^{\circ} \mathrm{C}$

In the following section, the effects of the cooling rate, strain rate and test temperature on the stress-strain response are discussed. Interpretations are based on microstructural evolution analysis (fraction and size of $\alpha_{I}$ nodules, $\alpha_{I I}$ lamellae or $\beta$ phase).

\subsubsection{Influence of the cooling rate}

As shown by many research works $[6,31]$ on the topic of microstructure evolution during cooling from temperatures above $950^{\circ} \mathrm{C}$, while the phase transformation $(\beta \leftrightarrow$ $\alpha$ ) mainly depends on the temperature, the cooling rate mainly affects the size of the primary $\alpha$ nodules as well as the initiation and growth of the $\alpha_{I I}$ phase, leading to different sizes and morphologies. Five tensile tests at different temperature levels $\left(\theta=\{950,800,700,500,300,20\}^{\circ} C\right)$ were conducted with a constant strain rate of $10^{-2} s^{-1}$. The present study shows that, during cooling, an important phase transformation of $\beta$ into $\alpha_{I I}$ occurs, mainly between $950^{\circ} \mathrm{C}$ and $900^{\circ} \mathrm{C}$. This result is confirmed by other research works $[32,33]$ and is illustrated in more detail in the 


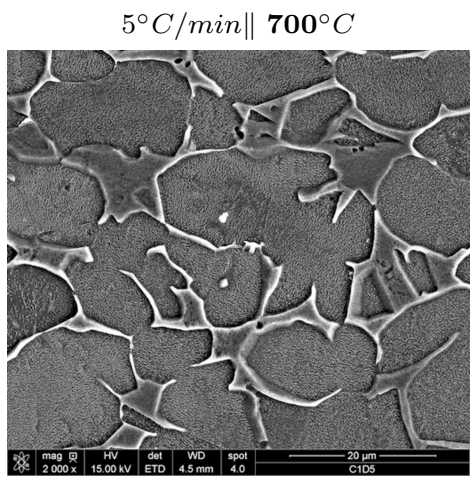

$5^{\circ} \mathrm{C} / \min \| \mathbf{2 0}^{\circ} \mathrm{C}$

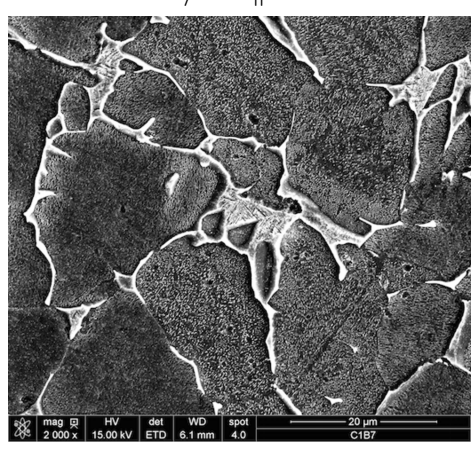

$60^{\circ} \mathrm{C} / \min \| \mathbf{7 0 0}{ }^{\circ} \mathrm{C}$

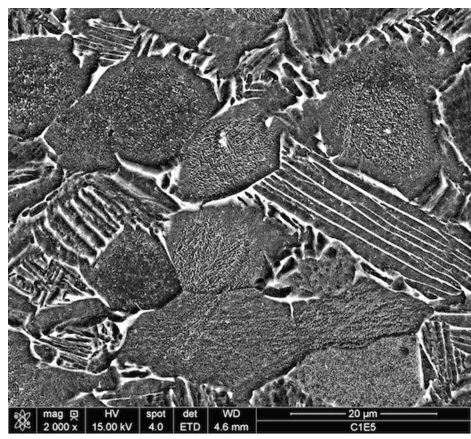

$60^{\circ} \mathrm{C} / \min \| \mathbf{2 0}^{\circ} \mathrm{C}$

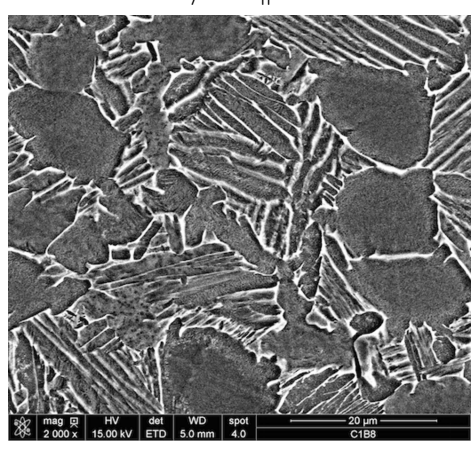

$200^{\circ} \mathrm{C} / \min \| \mathbf{7 0 0}^{\circ} \mathrm{C}$

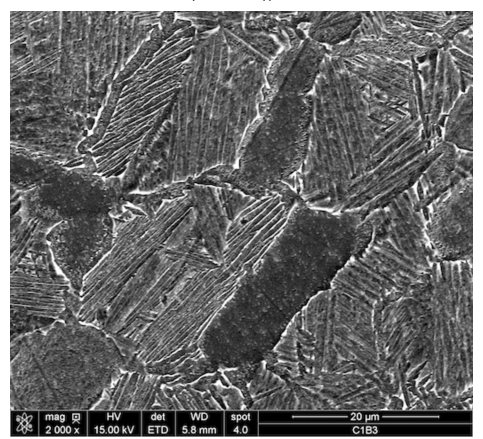

$200^{\circ} \mathrm{C} / \min \| \mathbf{2 0}^{\circ} \mathrm{C}$

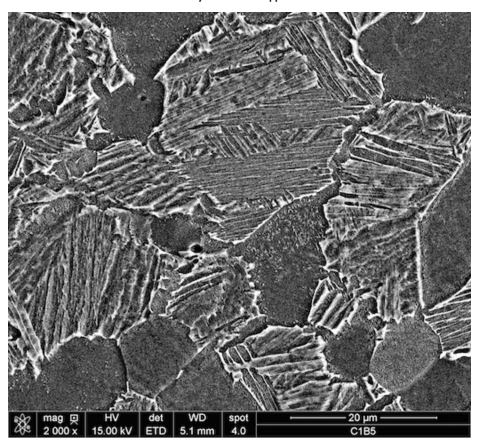

Figure 4: SEM observations for tensile tests performed at $700^{\circ} \mathrm{C}$ and $20^{\circ} \mathrm{C}$ for different cooling rates: $5^{\circ} \mathrm{C} / \min$ (left), $60^{\circ} \mathrm{C} / \min$ (center), $200^{\circ} \mathrm{C} / \min$ (right) [Kroll Reagent $\left.|\mathrm{SEM}| \times 2000\right]$

The corresponding tensile tests (see Fig. 5) show a significant hardening with the increase in the cooling rate. This feature can be related to the decrease in the $\alpha_{I I}$-lamellar thickness with the cooling rate. This induces a higher number of $\alpha / \beta$ boundaries that can act as more obstacles to the dislocation movements. This hardening is thus linked to the plasticity of the $\alpha$ phase $\left(\alpha_{I}\right.$ nodules and $\alpha_{I I}$ lamellae) as the evolution of the lamellar thickness can be related to the yield stress $[31,34,35]$ or to the hardness or the ductility of the material $[27,35]$. Image analysis was conducted to determine the $\alpha_{I I}$ lamellar thickness $L\left(\dot{\theta}=\{60,200\}^{\circ} \mathrm{C} / \mathrm{min}\right)$ and the $\alpha_{I}$ nodule size $\left(\dot{\theta}=5^{\circ} \mathrm{C} / \mathrm{min}\right)$. Fig. 6 illustrates the evolution of $\alpha_{I I}$-lamellae thickness $L$ for different cooling rates. As shown, this trend can be aligned to a power law. By plotting the curve given by Eq. 1 in a bi-logarithmic diagram, parameter $B$ can be determined from the value of the slope. Regarding the $\alpha_{I}$ nodules, the observations do not exhibit a significant evolution, regardless of the test conditions. The average size considered next is thus $15 \mu \mathrm{m}$. 


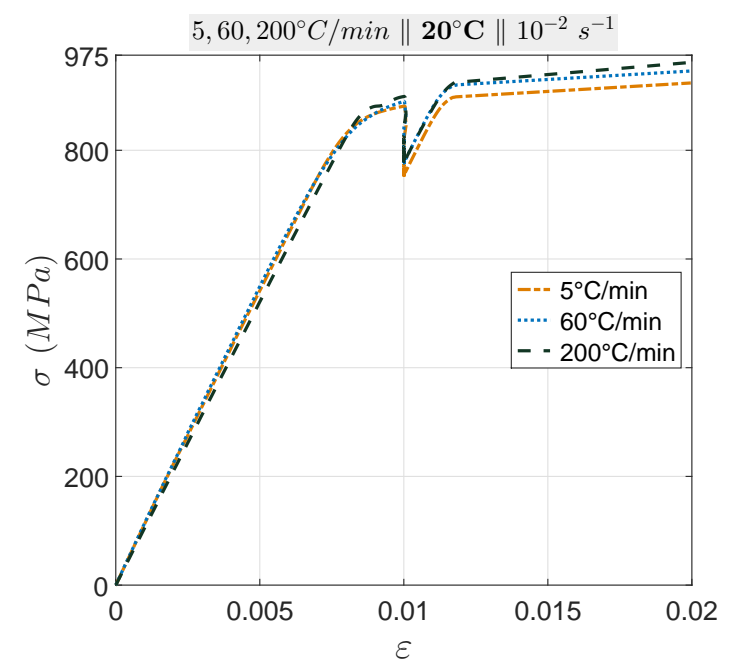

(a)

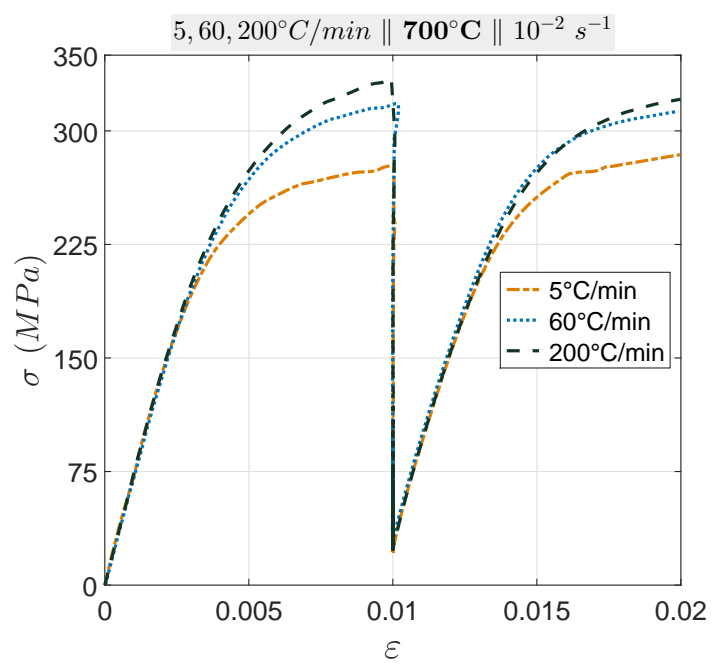

(b)

Figure 5: Stress-Strain response for different cooling rates at $20^{\circ} \mathrm{C}(\mathrm{a})$; and $700^{\circ} \mathrm{C}(\mathrm{b})$ and a constant strain rate of $10^{-2} s^{-1}$

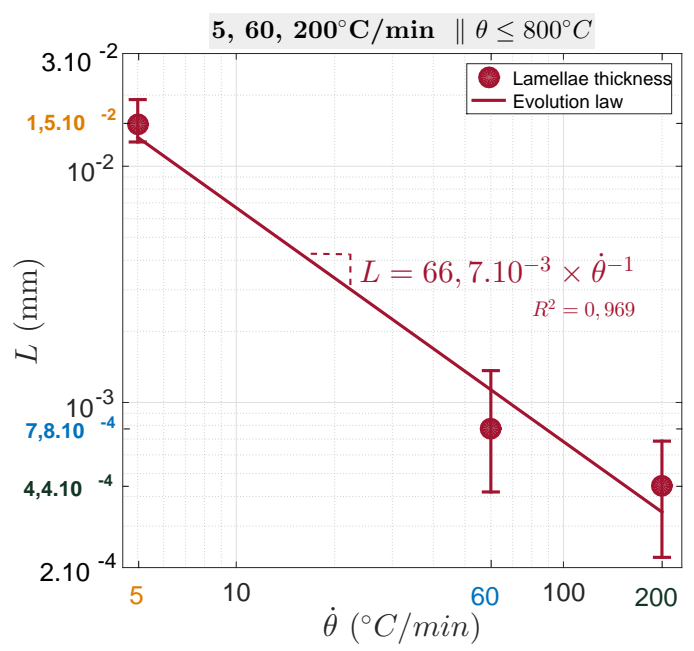

Figure 6: Evolution of the $\alpha_{I I}$-lamellae thickness with the cooling rate

$$
L=B \times \dot{\theta}^{-1}
$$

\subsubsection{Time effects: temperature and strain rate}

As mentioned previously, the phase transformation, in terms of fraction of phase, no longer evolves below $800^{\circ} \mathrm{C}$, as the transformation of $\beta$ into mainly $\alpha_{I I}$ lamellae occurs between $950^{\circ} \mathrm{C}$ and $800^{\circ} \mathrm{C}$, as shown in Fig. 7 .

At $950^{\circ} C$, the $\beta$ fraction can be deduced from the SEM images by analyzing the fraction of $\beta$ matrix $\beta_{H T}$ transformed through the fast cooling (air spraying) operated at the end of the mechanical test. At $900^{\circ} \mathrm{C}$, the measurements are complex, as the cooling time (from $950^{\circ} \mathrm{C}$ to $900^{\circ} \mathrm{C}$ ) is not long enough to clearly distinguish the transformed $\beta$ phase induced by the controlled cooling rate and the fast cooling from $900^{\circ} \mathrm{C}$ to $20^{\circ} \mathrm{C}$. Therefore, this temperature level will not be deeply investigated in 


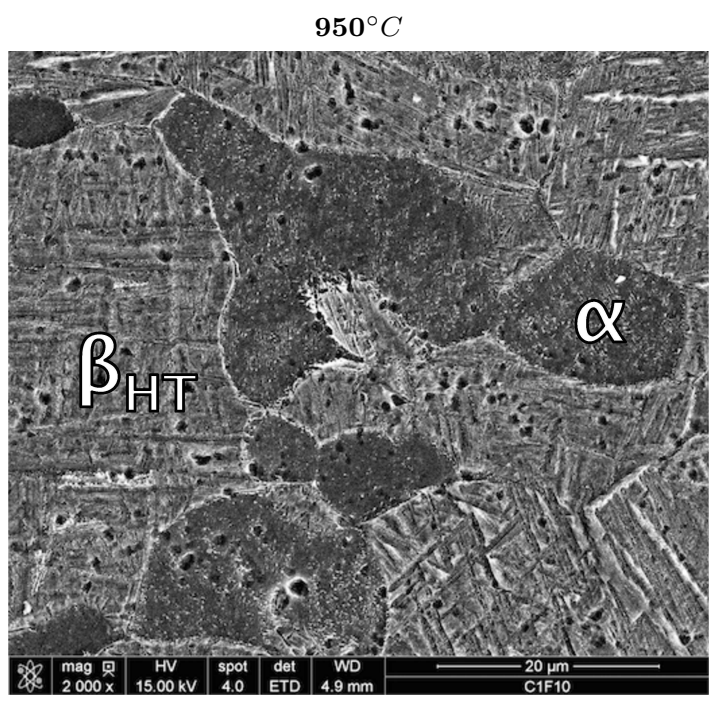

(a)

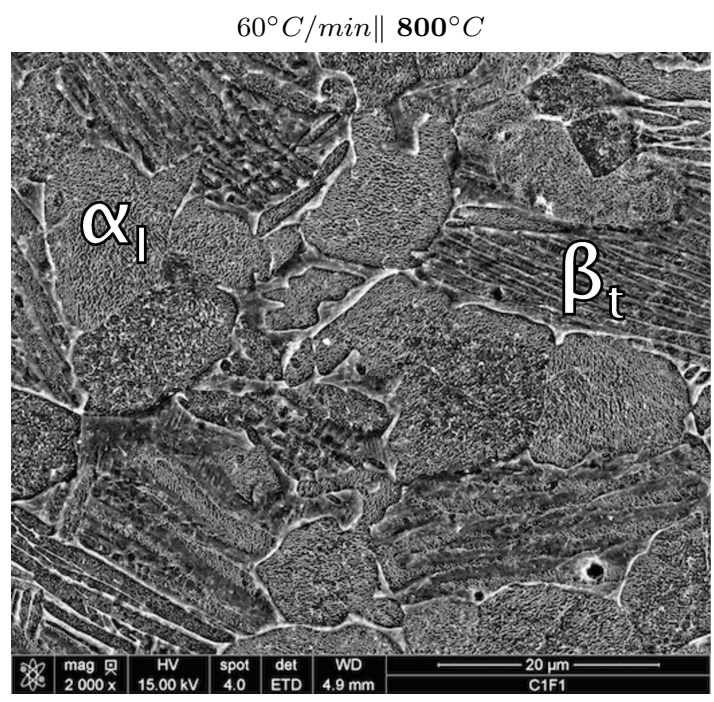

(b)

Figure 7: SEM observations for tensile tests performed at $950^{\circ} \mathrm{C}(\mathrm{a})$; and $800^{\circ} \mathrm{C}$ (b) for a cooling rate of $60^{\circ} \mathrm{C} / \min [$ Kroll Reagent $|\mathrm{SEM}| \times 2000]$

the sequel. From these measurements, the evolution of the $\beta$ fraction can be assessed (see Fig. 8).

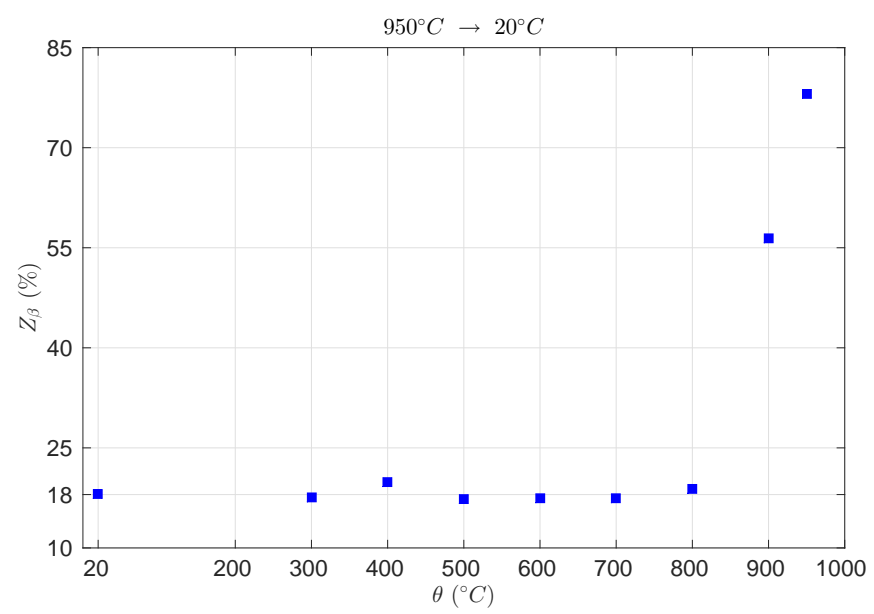

Figure 8: Evolution of the $\beta$-phase fraction with the temperature

These results are very similar to those provided in the work of Elmer [32] showing, in a Ti-6Al-4V alloy, the evolution with the temperature of the $\beta$ phase amounts measured by in situ X-ray diffraction techniques. As in our present study, it seems that most of the $\beta \leftrightarrow \alpha$ phase transformation occurs at a temperature in the $800^{\circ} C-T_{\beta}$ range. This therefore confirms that, during cooling, most of the $\beta$ phase had completed its transformation into $\alpha_{I I}$ phase around $800^{\circ} \mathrm{C}$. Regarding the mechanical behavior, as expected, the stress-strain curves show a decrease in the flow stress with the temperature (see Fig. 9). Moreover, a significant stress relaxation occurs during the tensile dwell time for the test temperature above $500^{\circ} \mathrm{C}$, involving considerable viscous stress, whereas it is considerably reduced below this temperature. 
Lastly, at $950^{\circ} \mathrm{C}$, a yield point phenomenon is observed. It is probably due to a pinning-depinning process of the dislocations in a Cottrell atmosphere [36, 37], as observed in BCC metals. Indeed, in BCC metals (as the $\beta$ phase), the dislocations can be pinned by interstitials, in which case a higher force is required in order to leave such dislocations away from their Cottrel atmosphere. Thus, during the first loading at $950^{\circ} \mathrm{C}$, this higher force is responsible for the upper yield point (stress peak). After unpinning, the dislocations can move easily at a lower stress leading to a slight stress softening. During the dwell time, the initial Cottrel atmosphere is recovered (static recovery) involving a new stress peak after the second loading. This phenomenon is predominant at $950^{\circ} \mathrm{C}$ where the mechanisms related to the $\beta$ phase play an important role, but vanishes at lower temperatures where the plastic deformation is mainly governed by the $\alpha$ phase.

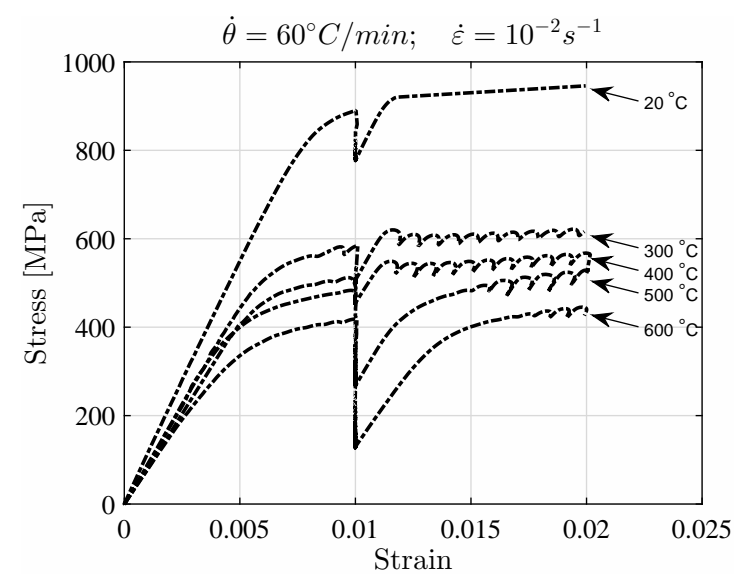

(a)

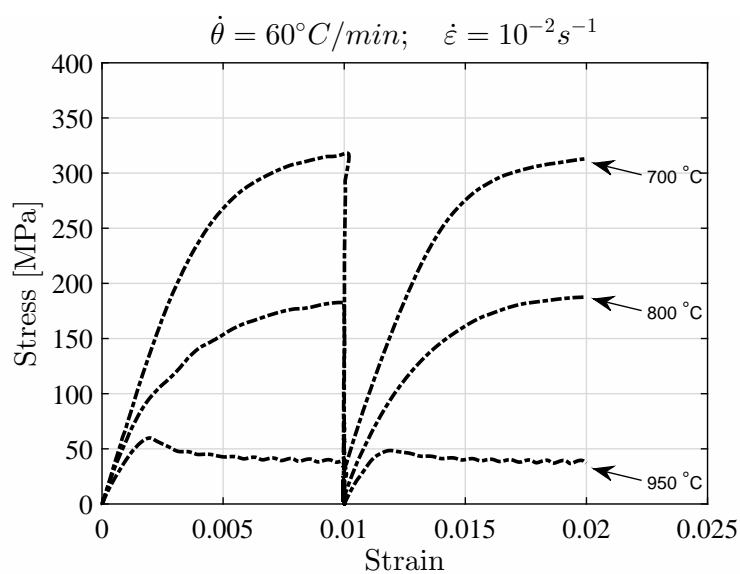

(b)

Figure 9: Stress-Strain response for constant strain $\left(10^{-2} s^{-1}\right)$ and cooling $\left(60^{\circ} \mathrm{C} / \mathrm{min}\right)$ rates at different temperatures $\theta \leq 600^{\circ} \mathrm{C}(\mathrm{a}) ; \theta \geq 700^{\circ} \mathrm{C}$ (b)

\section{Behavior modeling}

The previous analysis leads to the definition of 3 mechanisms acting on the mechanical behavior. The first one is related to the $\beta$ phase, whereas the two others are related to the $\alpha$ phase through the nodular part $\left(\alpha_{I}\right)$ and lamellar part $\left(\alpha_{I I}\right)$.

\subsection{Non-unified Constitutive Equations}

A homogeneous deformation (Eq. (2)) is assumed in each phase [14] and a strain partition of the total strain into elastic and plastic parts is considered (Eq. (3)).

$$
\begin{gathered}
\underline{\varepsilon^{t}}=\underline{\varepsilon_{\alpha_{I}}^{t}}=\underline{\varepsilon_{\alpha_{I I}}^{t}}=\underline{\varepsilon_{\beta}^{t}} \\
\underline{\varepsilon_{\phi}^{t}}=\underline{\varepsilon_{\phi}^{e}}+\underline{\varepsilon_{\phi}^{p}} \quad \forall \phi=\alpha_{I}, \alpha_{I I}, \beta
\end{gathered}
$$

Hooke's law is given by Eq. 4 for each phase. And each strain component can be related to a phase ratio $Z_{\Phi}$ (Eq. 5). 


$$
\begin{aligned}
& \underline{\sigma_{\phi}}=\underline{\underline{C_{\phi}}}\left(\underline{\varepsilon_{\phi}^{t}}-\underline{\varepsilon_{\phi}^{p}}\right) \quad \forall \phi \\
& \underline{\varepsilon^{e}}=\sum_{\phi} Z_{\phi} \underline{\varepsilon_{\phi}^{e} ;} \quad \underline{\varepsilon^{p}}=\sum_{\phi} Z_{\phi} \underline{\varepsilon_{\phi}^{p}} \quad \text { with: } \quad \sum_{\phi} Z_{\phi}=1 \quad \forall \phi
\end{aligned}
$$

A von Mises yield surface is assumed for each phase, as shown by Eq. 6. Its evolution is defined through an isotropic hardening variable $R_{\phi}$.

$$
f_{\phi}=\sigma_{\phi}^{e q}-R_{\phi}-\sigma_{\phi}^{0}=0 \quad \forall \phi
$$

$\sigma_{\phi}^{e q}$ and $\sigma_{\phi}^{0}$, are respectively the equivalent stress and the elasticity limit related to the phase $\phi$.

This approach is in agreement with the thermodynamics of the irreversible process defined by two potentials, the Helmotz free energy $\psi$ and the dissipation potential $\Omega$.

The free energy can be partitioned into elastic and inelastic parts $\psi=\psi^{e}+\psi^{\text {in }}$ and, in the present study, formulated for each phase (Eq. 7).

$$
\varrho \psi^{e}=\frac{1}{2} \sum_{\phi} Z_{\phi}^{2} \underline{\underline{C_{\phi}}} \underline{\underline{\varepsilon_{\phi}^{e}}}: \underline{\varepsilon_{\phi}^{e}} ; \quad \varrho \psi^{i n}=\frac{1}{2} \sum_{\phi} Z_{\phi}^{2} b_{\phi} Q_{\phi} r_{\phi}^{2} \quad \forall \phi
$$

The state laws giving the Cauchy stress and the macroscopic isotropic hardening variable derive from this potential (Eq. 8).

$$
\underline{\sigma}=\varrho \frac{\partial \psi^{e}}{\partial \underline{\varepsilon^{e}}}=\sum_{\phi} Z_{\phi} \underline{\sigma_{\phi}} ; \quad R=\varrho \frac{\partial \psi^{i n}}{\partial r}=\sum_{\phi} Z_{\phi} R_{\phi}=\sum_{\phi} Z_{\phi} b_{\phi} Q_{\phi} r_{\phi}
$$

with $r_{\phi}$ the internal variable associated to the isotropic hardening. $b_{\phi}$ and $Q_{\phi}$ are temperature-dependent coefficients.

The dissipation potential $\Omega$ allows definition of the evolution of the internal variables (Eq. 9). It includes, first, a static recovery part (Eq. 10) and a classical viscoplastic potential formulated in the form of a power law. However, its expression differs from one phase to another. Indeed, a similar form is used to describe the primary and secondary alpha phase (Eq. 11), whereas a particular form is considered for the $\beta$ phase (Eq. 12) so as to reproduce the yield point phenomenon.

$$
\begin{gathered}
\Omega=\sum_{\phi} Z_{\phi}^{2}\left(\Omega_{\phi}^{p}+\Omega_{\phi}^{r}\right) \quad \forall \phi \\
\Omega_{\phi}^{r}=\frac{a_{\phi} R_{\phi}^{2}}{2 b_{\phi} Q_{\phi}} \quad \forall \phi \\
\Omega_{\alpha}^{p}=\frac{K_{\alpha}}{n_{\alpha}+1}\left\langle\frac{f_{\alpha}}{K_{\alpha}}\right\rangle^{n_{\alpha}+1} \quad \forall \alpha=\alpha_{I}, \alpha_{I I}
\end{gathered}
$$

$$
\Omega_{\beta}^{p}=\frac{b_{\rho} \rho_{m}}{M} \frac{D}{n_{\beta}+1}\left\langle\frac{f_{\beta}}{D}\right\rangle^{n_{\beta}+1}
$$


$K_{\alpha}$ and $n_{\alpha}$ are temperature-dependent parameters of the phase $\alpha=\left(\alpha_{I}, \alpha_{I I}\right) . a_{\phi}$ defines the static recovery term in the hardening variables of each phase. Especially for the $\beta$-phase, $D$ is a material parameter, $b_{\rho}$ is the Burgers vector, $\rho_{m}$ the density of mobile dislocations and $M$ the Taylor factor.

The viscoplastic flow derives from this potential (Eq. 13).

$$
\underline{\dot{\varepsilon}^{p}}=\partial \Omega / \partial \underline{\sigma}=\sum_{\phi} Z_{\phi} \frac{3}{2} \frac{S_{\phi}}{\overline{\sigma_{\phi}^{e q}}} \dot{p}_{\phi}=\sum_{\phi} Z_{\phi} \underline{\dot{\varepsilon}_{\phi}^{p}} \quad \forall \phi
$$

where $S_{\phi}$ is the deviatoric part of $\sigma_{\phi}$.

The cumulative plastic strain for each phase is given by Eq. 14 for the $\alpha$ phase and Eq. 15 for the $\beta$ phase.

$$
\dot{p}_{\alpha}=\Omega_{\alpha}^{\prime}\left(f_{\alpha}\right)=\left\langle\frac{f_{\alpha}}{K_{\alpha}}\right\rangle^{n_{\alpha}} \forall \alpha=\alpha_{I}, \alpha_{I I}
$$

$$
\dot{p}_{\beta}=\Omega_{\beta}^{\prime}\left(f_{\beta}\right)=\frac{b_{\rho} \rho_{m}}{M}\left\langle\frac{f_{\beta}}{D}\right\rangle^{n_{\beta}}
$$

Lastly, the evolution equation related to the isotropic hardening for each phase is determined from Eq. 16.

$$
\dot{r}=-\partial \Omega / \partial R=\sum_{\phi} Z_{\phi} \dot{r}_{\phi} \quad \text { with: } \dot{r}_{\phi}=\dot{p_{\phi}}\left(1-b_{\phi} r_{\phi}\right)-a_{\phi} r_{\phi} \quad \forall \phi
$$

The positivity of $\mathcal{D}$ can be proved by Eq. 18 .

$$
\mathcal{D}=\sum_{\phi}\left(f_{\phi}+R_{\phi}+\frac{R_{\phi}^{2}}{Q_{\phi}}\right) \dot{p}_{\phi}+\sum_{\phi} \frac{a_{\phi}}{b_{\phi}}\left(\frac{R_{\phi}}{Q_{\phi}}\right)^{2} \geq 0
$$

\subsection{Introduction of the microstructural parameters}

The viscoplastic flows (Eq. 14 and 15) require the identification of material parameters for each phase, which were determined by using SEM observations and image analysis. Thus, the influence of the microstructural evolutions related to the cooling rate during the quenching stage can be introduced into the model formulation.

\subsection{1. $\alpha_{I}$ phase}

The proposed model acts on the coefficient $K_{\alpha_{I}}$ and establishes a relationship between this parameter and the average size of the primary $\alpha$ nodules $d_{\alpha_{I}}$, as shown by Eq. 19 following the Hall-Petch law.

$$
K_{\alpha_{I}}=K_{1} d_{\alpha_{I}}^{-n_{d}}
$$


with $K_{1}$ a temperature-dependent material parameter and $n_{d}$ the Hall-Petch coefficient, $n_{d}=0.5$.

\subsection{2. $\alpha_{I I}$ phase}

Similarly, the proposed law introduces a relationship, given by Eq. 20, between $K_{\alpha_{I I}}$ and the thickness of the $\alpha_{I I}$ lamellae $L$.

$$
K_{\alpha_{I I}}=K_{2} L^{-n_{L}}
$$

$K_{2}$ and $n_{L}$ are material parameters. $L$ depends on the cooling rate $\dot{\theta}$ (see Eq. $1)$.

\subsection{3. $\beta$ phase}

The mobile dislocations are at the root of the yield point phenomenon [24] and the density of these dislocations $\rho_{m}$ is a part $f_{m}$ of the density of the total dislocations $\rho_{t}$ (Equation 21). Moreover, this part evolves between a starting value $f_{m 0}$ and an asymptotic value $f_{m a}$ [38]. Finally, an empirical law is used to define the relation between the densities of the total dislocations and the cumulative plastic strain.

$$
\rho_{m}=f_{m} \rho_{t} ; \quad \rho_{t}=\rho_{0}+C_{\rho} p_{\beta}
$$

where $C_{\rho}$ and $a_{\rho}$ are material parameters.

The strain rate had a significant influence on the yield point phenomenon, therefore, the following time evolution of $f_{m}$ is assumed (Equation 22).

$$
\dot{f_{m}}=-\lambda \dot{p}_{\beta}^{\kappa}\left(f_{m}-f_{m a}\right)
$$

with: $f_{m}(t=0)=f_{m 0}$ and $\lambda$ and $\kappa$ are material parameters.

This equation differs from the literature [14]. Indeed, in the present study, the yield point phenomenon increases with the strain rate, which is an effect that has not been observed on steels [24, 25] or on metastable $\beta$-titanium alloys [21, 22].

As shown previously, the tensile dwell time induces a stress relaxation which can be reproduced by introducing a static recovery term into the isotropic hardening component. This phenomenon involves a dislocations rearrangement with a decrease in the dislocation density [39-41]. Moreover, during this dwell time at high temperature, some interstitial atoms can diffuse back around the dislocations, leading to the re-pinning of dislocations in the Cottrel atmosphere. Therefore, the yield point phenomenon is again observed during the second loading. In order to account for this effect in the model formulation, Eq. 22 is modified by Eq. 23 and a static recovery term is added, describing the decrease in the density of the mobile dislocations during dwell time.

$$
\dot{f_{m}}=-\lambda \dot{p}_{\beta}^{\kappa}\left(f_{m}-f_{m a}\right)-\mu f_{m}^{\delta}
$$

where $\mu$ and $\delta$ are material parameters.

All the constitutive equations are given in Appendix A (table A.1). 


\section{Results}

\subsection{Identification Strategy}

\subsubsection{Young's Modulus}

The evolution of Young's modulus with the temperature is obtained by using the relationship given by Eq. 24 .

$$
E=\left(Z_{\alpha_{I}}+Z_{\alpha_{I I}}\right) E_{\alpha}+Z_{\beta} E_{\beta}
$$

The same values are assumed for $\alpha_{I}$ nodules and $\alpha_{I I}$ lamellae. A tensile test at $1030^{\circ} \mathrm{C}$ was performed to determine the modulus of the $\beta$-treated alloy. A literature review [15, 42-45] allows Young's modulus evolution to be determined at lower temperatures. Then, knowing the phase fraction $Z_{\phi}$, the Young's modulus values of the $\alpha$ phase are deduced from Eq. 24. The results obtained are in a good agreement with the values found in the literature, as shown in Fig. 10.

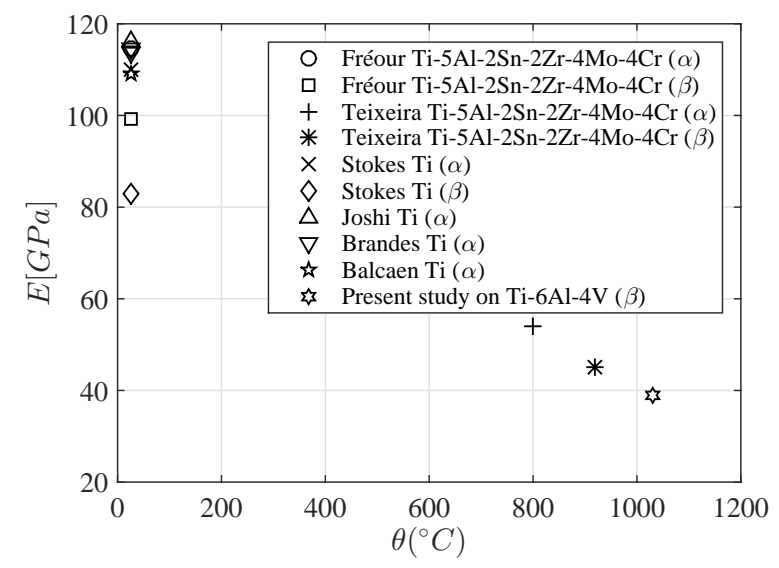

(a)

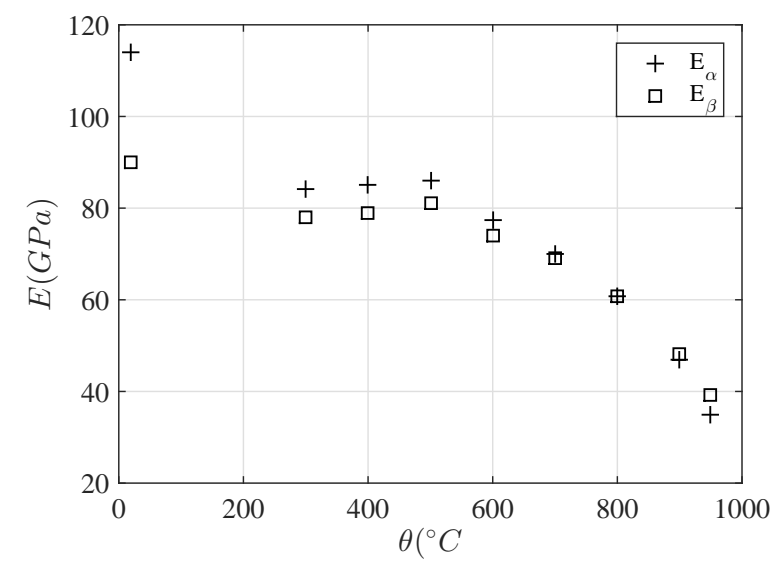

(b)

Figure 10: Temperature evolution of Young's modulus for $\alpha$ and $\beta$ phases: (a) literature (b) values used in this study

\subsubsection{Time-dependent parameters}

The tensile tests performed with a cooling rate of $60^{\circ} \mathrm{C} / \mathrm{min}$ were used to identify the viscous parameters $K_{\phi}$ and $n_{\phi}$. The stress relaxation curves $\sigma-\sigma_{i}=f($ time $)$ were plotted in a bi-logarithmic diagram to determine these parameters for temperature level, where $\sigma_{i}$ is the non-viscous stress corresponding to the stabilized stress value at the end of the relaxation time. The static recovery term $a_{\phi}$ of the isotropic hardening variable allows a better description of the relaxation curve, as shown in Fig. 11. This term $a=a_{\phi}$ is assumed to be equal for each phase and is obtained by an optimization procedure for each temperature level.

The curve gives the value of $n=n_{\phi}$, which is assumed to be the same for each phase. The $K_{\phi}$ parameter depends on the phase, as shown in Eq. 19 and 20. Assuming $K_{\alpha_{I}}=K_{\alpha_{I I}}$ given by the bi-logarithmic curve, $L$ (provided by Eq. 1) and $d_{\alpha_{I}}$, obtained by image analysis, one can determine, on the one hand, $K_{1}$ for the $\alpha_{I}$ nodules, and on the other hand, $K_{2}$ and $n_{L}$ for the $\alpha_{I I}$ lamellae. It can be observed that Eq. 19 corresponds to a Hall-Petch law and the coefficient 


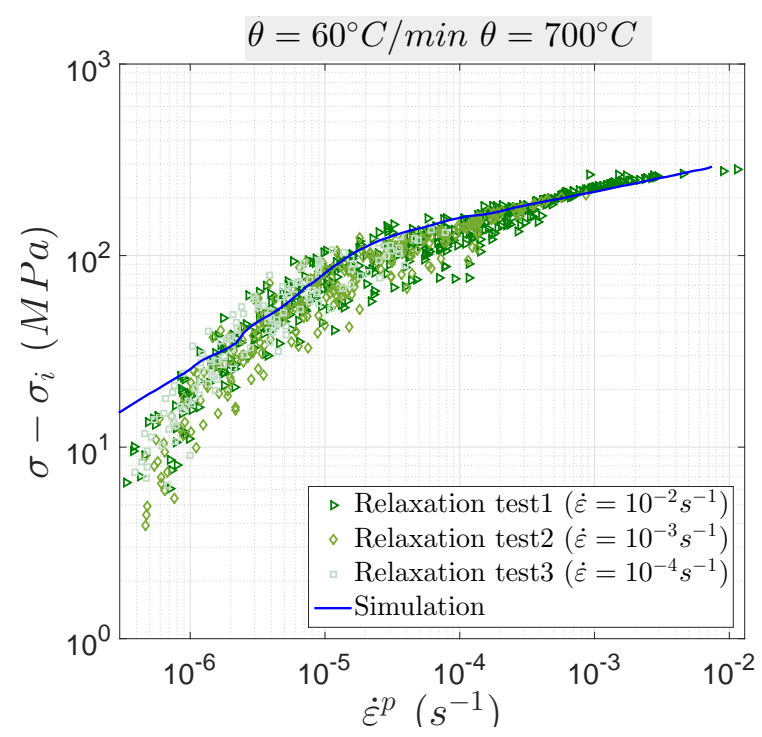

Figure 11: Comparison between the relaxation range provided by the model and the experiment for a cooling rate of $60^{\circ} \mathrm{C} / \mathrm{min}$ and a temperature of $700^{\circ} \mathrm{C}$

$n_{d}$ is equal to 0.5. Moreover, the $D$ parameter for the $\beta$ phase is obtained by taking $Z_{\beta}=1$. Then, a rule of mixtures between phases gives a weighting of the parameters related to each phase. To consider the yield point phenomenon in the model formulation induced at high temperature, some additional paramaters need to be identified. The values of the Burgers vector $b_{\rho}$ and of the Taylor factor M come from the work of Wang for a titanium alloy [21]. Moreover, the parameters related to the dislocation densities $\rho_{0}, C_{\rho}$ and $f_{m 0}$ are also found in the literature [22]. Lastly, the parameter $a_{\rho}$ is identified from the tests performed at $950^{\circ} \mathrm{C}$ and $900^{\circ} \mathrm{C}$, its value is usually between 0.7 and $1.5[24,37,39]$. The parameters $\lambda, \delta$, $\kappa$ and $\mu$ related to the volume fraction of mobile dislocation are also identified at $950^{\circ} \mathrm{C}$ and $900^{\circ} \mathrm{C}$ where the yield point phenomenon is observed, they are selected to fit the stress-strain curve and are determined by an optimization procedure. The volume fraction of mobile dislocations $f_{m}$ evolves between an initial value $f_{m 0}$ and an asymptotic one $f_{m a}[24,25] . f_{m 0}$ is constant with the temperature, whereas $f_{m a}$ decreases in order to take into account the decrease in the mobile dislocations density at lower temperatures. This evolution will only be activated at $950^{\circ} \mathrm{C}$ and $900^{\circ} \mathrm{C}$ in order to consider the yield point phenomenon. For the other temperature levels, this phenomenon vanishes by taking $f_{m a}=f_{m 0}$.

\subsubsection{Hardening parameters}

The parameters $Q=Q_{\phi}$ and $b=b_{\phi}$ of the isotropic hardening variable and the elasticity limit $\sigma^{0}=\sigma_{\phi}^{0}$ are assumed to be equal for each phase. An optimization procedure is used for a cooling rate of $60^{\circ} \mathrm{C} / \mathrm{min}$ considering the whole database.

\subsection{Results}

\subsubsection{Model prediction on $(\alpha+\beta)$ Ti-6Al-4V}

Fig. 12 illustrates a comparison between simulation and experiment at $950^{\circ} \mathrm{C}$. At this temperature, the mechanism related to the $\beta$ phase is predominant and the 
modified version of the Yoshida model (Eq. 15, 21, 22) presented in the previous section allows a good description of the behavior at different strain rates.

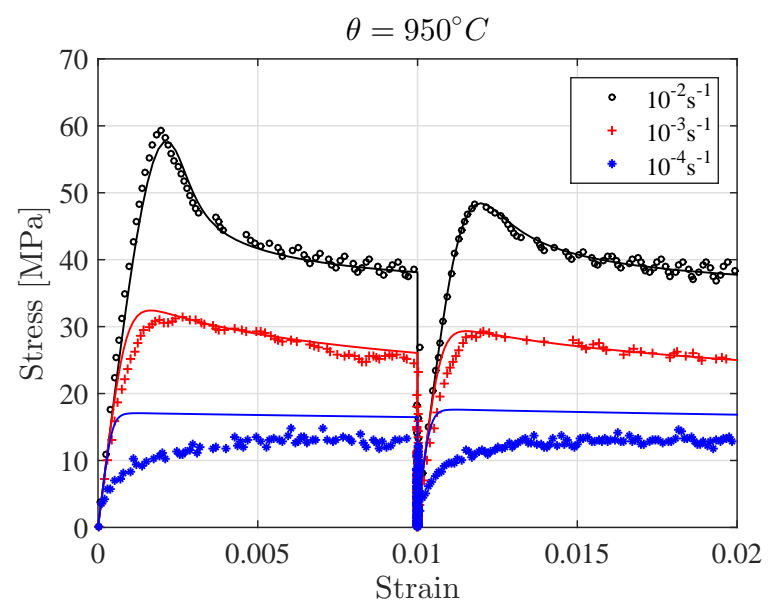

Figure 12: Yield point prediction at $950^{\circ} \mathrm{C}$ and several strain rates (line: simulation, marker: experiment

For a cooling rate of $60^{\circ} \mathrm{C} / \mathrm{min}$ the model response is in a good agreement with the experiment at lower temperatures and different strain rates, as shown in Fig. $13 \mathrm{a}$ at $800^{\circ} \mathrm{C}$ and in Fig. $13 \mathrm{~b}$ at $700^{\circ} \mathrm{C}$.

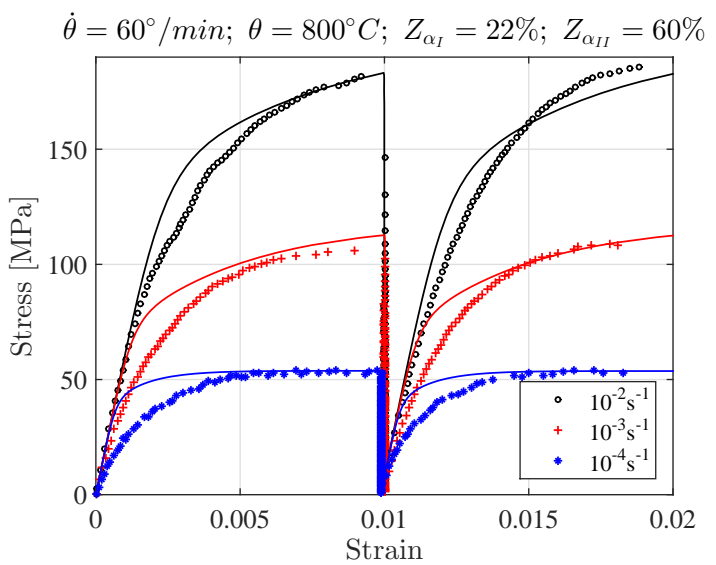

(a)

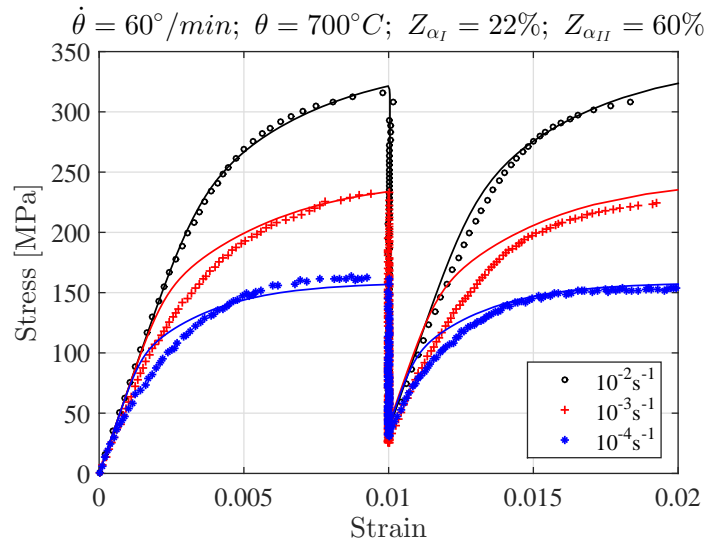

(b)

Figure 13: Computed Strain-Stress data (line) compared to Experimental results (marker) for several strain rates and at $\theta=800^{\circ} \mathrm{C}$ (a); $\theta=700^{\circ} \mathrm{C}$ (b).

Lastly, the model predictions for several cooling rates are illustrated in Fig. 14 at $\theta=500^{\circ} \mathrm{C}$ (a) and at $\theta=20^{\circ} \mathrm{C}$ (b).

All the values of the model parameters are given in Appendix B (Tables B.2-B.6).

\subsubsection{Model extension on $\beta$-treated Ti-6Al-4 $\mathrm{V}$}

In this section, the model is extended to a $\beta$-treated alloy. For this purpose, an experimental test campaign similar to the previous one was performed. It used the same starting samples obtained after the Forging operation (see Fig. 1) but the experimental procedure was changed by considering a solution annealing at 


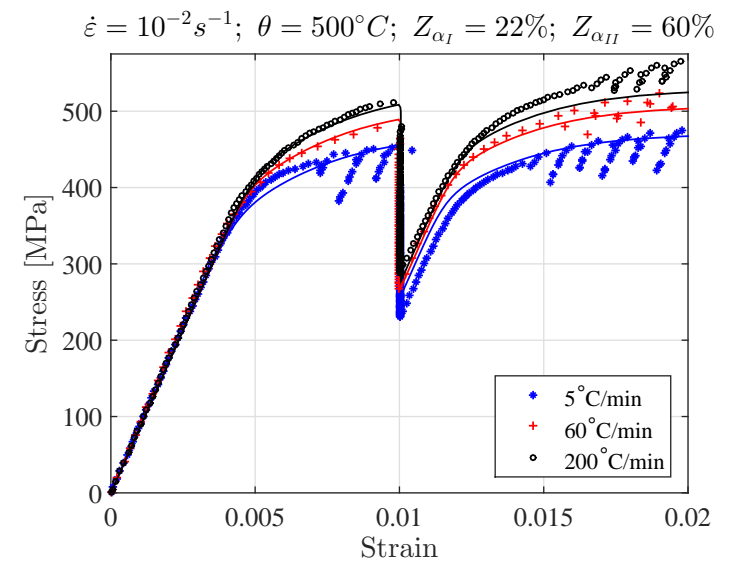

(a)

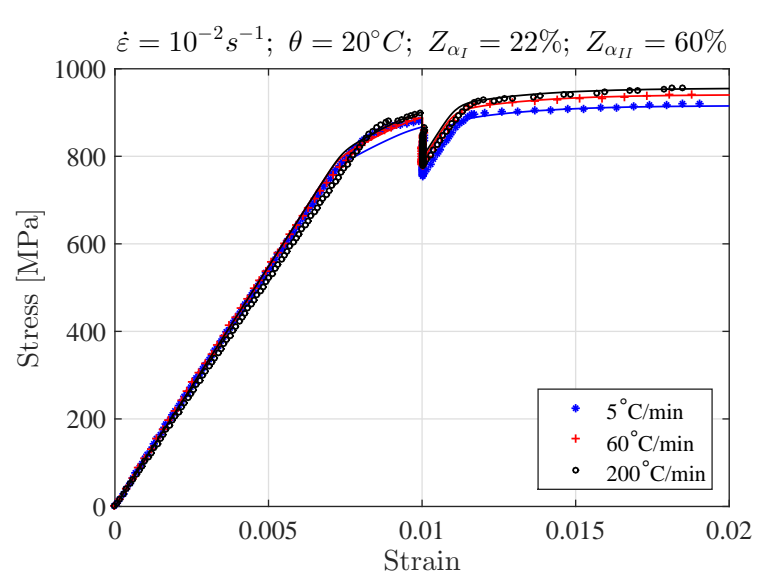

(b)

Figure 14: Computed Strain-Stress data (line) compared to Experimental results (marker) for several cooling rates and at $\theta=500^{\circ} \mathrm{C}$ (a); $\theta=20^{\circ} \mathrm{C}$ (b).

$1030^{\circ} \mathrm{C}$ above the $\beta$-transus temperature $\left(T_{\beta}=1000^{\circ} \mathrm{C}\right)$. In this case, all the model parameters related to the $\beta$-phase are identified at $1030^{\circ} C$ (see table C.7). At this temperature, the parameters of the mechanical model are $\alpha$-phase independent, therefore $Z_{\alpha_{I}}=Z_{\alpha_{I I}}=0$. For the other temperature levels, the model prediction was made by maintaining the values of almost all the model parameters identified for the $(\alpha+\beta)$ heat treatment (Tables B.2-B.6). Only the microstructural parameters (Table C.8) related to the phase fractions $Z_{\Phi}$ and the evolution of lamellae morphology $L$ with the cooling rate needed to be identified again from SEM image analysis in order to investigate the $\beta$-heat-treated alloy. The mechanism related to the $\alpha_{I}$ nodules vanished in this case $\left(Z_{\alpha_{I}}=0\right)$, as during the solid solution annealing at $1030^{\circ} \mathrm{C}$ where all the $\alpha_{I}$ nodules were transformed into $\beta$. Then, during cooling below the $\beta$-transus temperature, the $\beta$ phase was finally transformed into a fully lamellar $(\alpha+\beta)$ microstructure.

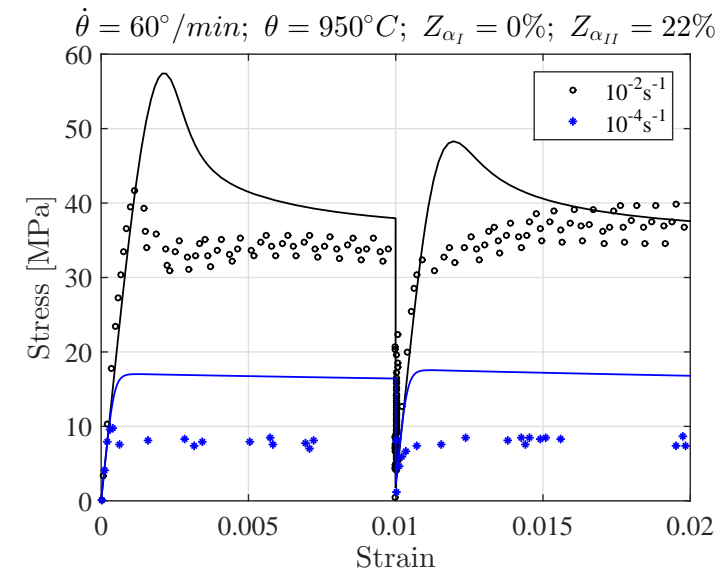

(a)

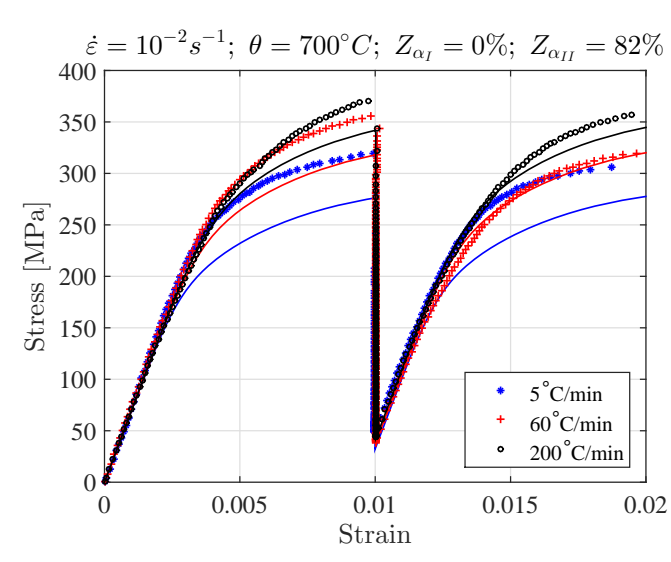

(b)

Figure 15: Computed Strain-Stress data (line) compared to Experimental results (marker) at $\theta=950^{\circ} \mathrm{C}$ and several strain rates (a); at $\theta=700^{\circ} \mathrm{C}$ and several cooling rates (b). 


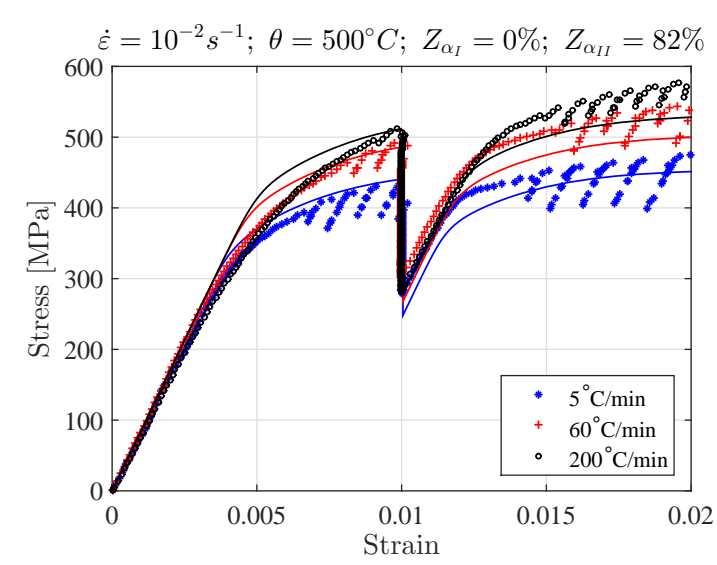

(a)

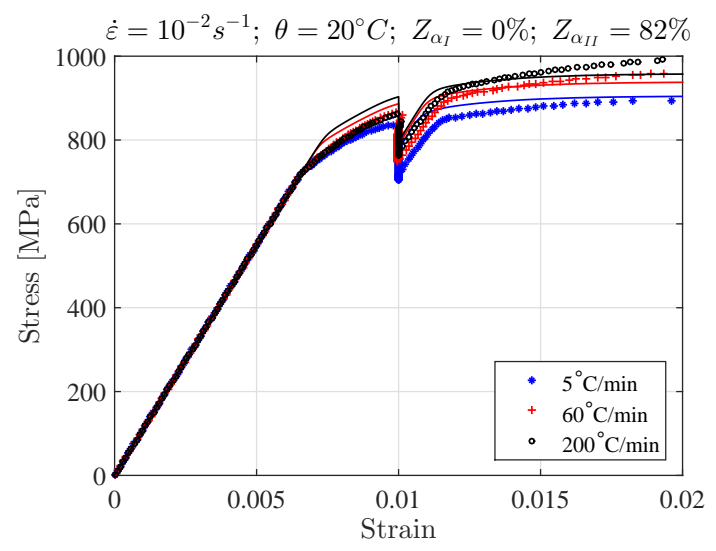

(b)

Figure 16: Computed Strain-Stress data (line) compared to Experimental results (marker) for several cooling rates and at $\theta=500^{\circ} \mathrm{C}$ (a); $\theta=20^{\circ} \mathrm{C}$ (b).

Fig. 15 and Fig. 16 illustrate the comparison between the computed StrainStress data and experimental results in the case to the $\beta$-heat treated Ti-6Al-4V, at $950^{\circ} \mathrm{C}$ and for several strain rates (Fig. 15a), at intermediate temperatures $\left(\mathrm{T}=\{20,500,700\}^{\circ} \mathrm{C}\right)$ and for several cooling rates (Fig. 15b and 16a-b). Aside from the temperature of $950^{\circ} \mathrm{C}$ where the stress levels are very low, discrepancies between the model response and the experiment were less than $15 \%$ for the other test conditions. This is is quite acceptable since the only parameters that have to be changed concern microstructural features of the $\beta$-heat treated alloy.

\subsection{Discussion}

The quenching of industrial parts generates transient temperature variations that induce plastic straining due to thermal self-constraining. The degree of selfconstraining depends on the dimensions of a part and on the heat transfer mechanisms between the part and the quenching environment (for example oil or water quenching ...) that control the mean global cooling rate [46]. In general the residual stresses are investigated at room temperature, and can be measured through X-Ray Diffraction or hole drilling methods. In-situ measurements of the residual stresses are not possible and the only rational manner is to use advanced thermo-mechanical modeling and numerical simulations analysis. Therefore relevant and reliable constitutive laws have to be developed. However, alloys such as Ti-6Al-4V alloy are very much prone to microstructural evolution at high temperature or during transient temperature-time conditions. In many approaches, the reliability of the constitutive laws is examined by laboratory testing of heat-treated alloys. The high temperature assessments are thus run on specimens heated up again to a prescribed temperature for mechanical testing. In the present investigation, the main objective was to assess and to model the thermo-mechanical behavior of Ti-6Al- $4 \mathrm{~V}$ alloy, through stepwisetemperature mechanical testing by first conducting an in-situ heat-treatment and then by quenching with a controlled rate to a prescribed temperature and finally by conducting the mechanical testing at this temperature. Such combining of timetemperature-mechanical scenarios are not commonly reported in the literature and often absent in the open literature. Although, many investigations deal with the 
mechanical behavior of Titanium alloys especially Ti-6Al-4V alloy, most of them consider the thermodynamic equilibrium conditions. However, some comparisons can be made with the present study considering the influence of the microstructure on the mechanical response of the material.

First, the phase analysis (Fig. 8) illustrates a drastic decrease of the $\beta$ phase from 950 to $800^{\circ} \mathrm{C}$ with a $\beta$ phase around $78 \%$ at $950^{\circ} \mathrm{C}$. Similar results are found in the literature at this temperature $[32,33]$. This means that the role of the $\beta$ phase cannot be neglected and the plasticity induced has to be linked to this phase. The yield point phenomenon illustrated in Fig. 12 is observed on many Body-Centered Cubic (BCC) materials $[39,41]$ such as the $\beta$ phase for titanium alloys. It can be related to the dislocations locked by the solute atoms then broken away from the pinning points at a high stress level. It is also associated with discontinuous yielding with the increase of new mobile dislocations generated from the grain boundary $[20,21,47,48]$. The behavior model implemented in the present study is based on a rule of mixture between two mechanisms, one related to the $\alpha$ phase (divided in primary and secondary phases), the second to the $\beta$ phase. At high temperatures, the constitutive equations associated with the $\beta$ phase are predominant, and the formulation is based on the works performed by Yoshida et al on BCC materials $[21,22,24,25]$. As discussed previously, these equations are modified to take into account some particular effects observed, such as the increase of the yield point with the strain rate and the dislocations rearrangement with a decrease in the dislocation density during dwell times (see Eq. 23).

Secondly, at lower temperatures, the effect of the $\alpha$ phase increases while that of the $\beta$ phase decreases. Moreover, Fig. 4 shows a decrease of the $\alpha_{I I}$-lamellar thickness with the cooling rate involving an increase of the flow stress (Fig. 5). This result is induced by an increase of the $\alpha / \beta$ boundaries acting as obstacles to the dislocation movements. These results are also shown in several investigations $[28,35,49]$. This effect is described in the constitutive equations through the viscous flow where the $K_{\Phi}\left(\Phi=\left\{\alpha_{I}, \alpha_{I I}\right\}\right)$ parameter evolves with the thickness of the $\alpha_{I I}$ lamellae $L$ (see Eq. 20), itself related to the cooling rate, or with the average size of the primary $\alpha$ nodules $d_{\alpha_{I}}$ (Eq. 19).

Finally, the strain rate sensitivity is reduced for temperatures inferior to $500^{\circ} \mathrm{C}$ [8] involving a significant hardening effect which is assumed similar for each phase. On the other hand, Fig. 12 and 13 show an important strain rate effect for the temperatures exceeding $600^{\circ} \mathrm{C}$ as mentioned in [3] compared to the hardening effect.

\section{Conclusions}

In the present work, an experimental device was developed to reproduce the mechanical behavior of Ti-6Al-4V throughout the die-forging operation. A nonunified behavior model was implemented and the following conclusions can be drawn.

- For a $(\alpha+\beta)$ dual-phase alloy, the phase transformation is greatly influenced by the cooling rate conditions, which themselves play an important role in the strain-stress response of the material.

- The non-unified behavior model is able to predict the mechanical behavior, assuming an initial phase proportion $\left(\alpha_{I}, \alpha_{I I}\right.$ or $\left.\beta\right)$. 


\section{Acknowledgement}

441 The authors very much acknowledge the financial support received through an 442 FUI grant in the framework of the collaborative project TiMaS (Titanium Machining 443 and Simulation), led by Airbus. The authors also gratefully acknowledge Figeac Aéro

444 for the machining of samples. 


\section{Appendix A. Model summary}

The table A.1 summarizes the model formulation.

Table A.1: non-unified model formulation

\begin{tabular}{|c|c|c|}
\hline & Multi-axial formulation & Uni-axial formulation \\
\hline Yield criterion & $f_{\phi}=\sigma_{\phi}^{e q}-R_{\phi}-\sigma_{\phi}^{0} \quad \forall \phi$ & $f_{\phi}=\left|\sigma_{\phi}\right|-R_{\phi}-\sigma_{\phi}^{0}$ \\
\hline Hooke's law & $\underline{\sigma_{\phi}}=\underline{\underline{C_{\phi}}}\left(\underline{\varepsilon_{\phi}^{t}-\varepsilon_{\phi}^{p}}\right) \quad \forall \phi$ & $\sigma_{\phi}=E_{\phi}\left(\varepsilon_{\phi}^{t}-\varepsilon_{\phi}^{p}\right)$ \\
\hline Flow rules & $\begin{array}{c}\frac{\dot{\varepsilon}^{p}}{=}=\sum_{\phi} Z_{\phi}^{2} \frac{3}{2} \frac{\sigma_{\bar{\phi}}}{\overline{\sigma_{\phi}^{e q}}} \dot{p}_{\phi} \quad \forall \phi \\
\text { with } \dot{p}_{\alpha}=\left\langle\frac{f_{\alpha}}{K_{\alpha}}\right\rangle^{n_{\alpha}} \quad \forall \alpha=\alpha_{I}, \alpha_{I I} \\
\text { and } \dot{p}_{\beta}=\frac{b_{\rho} \rho_{m}}{M}\left\langle\frac{f_{\beta}}{D}\right\rangle^{n_{\beta}}\end{array}$ & $\begin{array}{c}\dot{\varepsilon}^{p}=\sum_{\phi} Z_{\phi} \dot{p}_{\phi} \operatorname{sign}\left(\sigma_{\phi}\right) \quad \forall \phi \\
\text { with } \dot{p}_{\alpha}=\left\langle\frac{f_{\alpha}}{K_{\alpha}}\right\rangle^{n_{\alpha}} \\
\text { and } \dot{p}_{\beta}=\frac{b_{\rho} \rho_{m}}{M}\left\langle\frac{f_{\beta}}{D}\right\rangle^{n_{\beta}}\end{array}$ \\
\hline $\begin{array}{c}\text { Microstructural } \\
\text { parameters }\end{array}$ & \multicolumn{2}{|c|}{$K_{\alpha_{I I}}=K_{2} L^{-n_{L}} \quad$ with $\quad L=B \dot{\theta}^{-1}$} \\
\hline $\begin{array}{l}\text { Metallurgical } \\
\text { parameters }\end{array}$ & \multicolumn{2}{|c|}{ 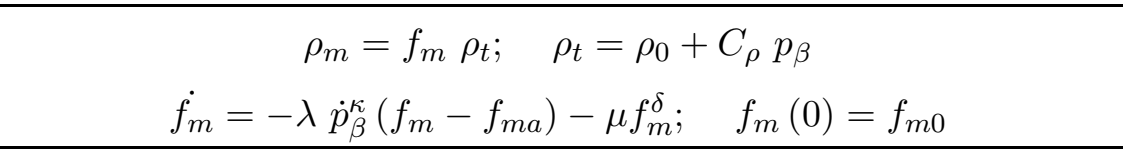 } \\
\hline Isotropic hardening & \multicolumn{2}{|c|}{$\begin{array}{c}\dot{r}=-\sum_{\phi} Z_{\phi} \dot{r}_{\phi} \text { with } \dot{r}_{\phi}=\dot{p_{\phi}}\left(1-b_{\phi} r_{\phi}\right)-a_{\phi} r_{\phi} \\
\text { and } R_{\phi}=b_{\phi} Q_{\phi} r_{\phi} \quad \forall \phi\end{array}$} \\
\hline
\end{tabular}




\section{Appendix B. Model coefficients for $\alpha+\beta$ treated Ti-6Al-4V}

Table B.2 illustrates the phase-independent model parameters, tables B.3 and B.4 the $\alpha$-phase dependent model parameters and tables B.5 and B.6 $\beta$-phase dependent model parameters

Table B.2: Phase independent and temperature dependent model parameters

\begin{tabular}{|c|c|c|c|c|c|c|c|c|c|}
\hline$\theta\left[{ }^{\circ} \mathrm{C}\right]$ & 950 & 900 & 800 & 700 & 600 & 500 & 400 & 300 & 20 \\
\hline$\sigma^{0}[\mathrm{MPa}]$ & 1 & 1 & 3 & 10 & 34 & 145 & 327 & 386 & 650 \\
\hline$Q[\mathrm{MPa}]$ & 1 & 2 & 55 & 85 & 92 & 97 & 100 & 101 & 103 \\
\hline$b$ & 1 & 5 & 190 & 317 & 400 & 425 & 433 & 434 & 435 \\
\hline$a\left[s^{-1}\right]$ & $510^{-1}$ & $2.510^{-1}$ & $8.10^{-2}$ & $210^{-2}$ & $810^{-3}$ & $310^{-3}$ & $210^{-4}$ & $1.410^{-4}$ & $410^{-5}$ \\
\hline$n$ & 3.3 & 3.4 & 3.6 & 4.9 & 7.8 & 9.8 & 11.2 & 11.7 & 12 \\
\hline
\end{tabular}

Table B.3: $\alpha$-phase and temperature dependent model parameters (1)

\begin{tabular}{|c|c|c|c|c|c|c|c|c|c|}
\hline$\theta\left[{ }^{\circ} \mathrm{C}\right]$ & 950 & 900 & 800 & 700 & 600 & 500 & 400 & 300 & 20 \\
\hline$E_{\alpha}[G P a]$ & 35 & 47 & 60.7 & 70 & 77.4 & 86 & 85.1 & 84.1 & 109.5 \\
\hline$Z_{\alpha_{I I}}$ & 0 & 0.22 & \multicolumn{7}{|c|}{0.44} \\
\hline$K_{1}$ & 23.7 & 24 & 62.8 & 77.3 & 73.5 & 51.5 & 20.8 & 20.2 & 32.3 \\
\hline$K_{2}$ & 95 & 96 & 251 & 309 & 294 & 208 & 83 & 81 & 131 \\
\hline
\end{tabular}

Table B.4: $\alpha$-phase dependent model parameters (2)

\begin{tabular}{|c|c|c|c|c|}
\hline$Z_{\alpha_{I}}$ & $d_{\alpha_{I}}[\mathrm{~mm}]$ & $n_{d}$ & $n_{L}$ & $B$ \\
\hline 0.22 & $15.10^{-3}$ & 0.5 & 0.105 & $66.710^{-3}$ \\
\hline
\end{tabular}

Table B.5: $\beta$-phase and temperature dependent model parameters (1)

\begin{tabular}{|c|c|c|c|c|c|c|c|c|c|}
\hline$\theta\left[{ }^{\circ} \mathrm{C}\right]$ & 950 & 900 & 800 & 700 & 600 & 500 & 400 & 300 & 20 \\
\hline$E_{\beta}[G P a]$ & 39.3 & 48.2 & 60.7 & 69 & 74 & 81 & 79 & 78 & 90 \\
\hline$D$ & 181 & 182 & 370 & 472 & 493 & 372 & 160 & 148 & 290 \\
\hline$Z_{\beta}$ & 0.78 & 0.56 & \multicolumn{7}{|c|}{0.18} \\
\hline$f_{m a}$ & $5.10^{-3}$ & $1.10^{-3}$ & $5.510^{-4}$ & $4.510^{-4}$ & \multicolumn{5}{|c|}{$40^{-4}$} \\
\hline
\end{tabular}

Table B.6: $\beta$-phase dependent model parameters (2)

\begin{tabular}{|c|c|c|c|c|c|c|c|c|}
\hline$b_{\rho}[\mathrm{cm}]$ & $M$ & $\rho_{0}\left[\mathrm{~cm}^{-2}\right]$ & $C_{\rho}\left[\mathrm{cm}^{2}\right]$ & $f_{m 0}$ & $\lambda$ & $\kappa$ & $\mu$ & $\delta$ \\
\hline $2.510^{-8}$ & 2.76 & $6.410^{10}$ & $2.110^{11}$ & $410^{-4}$ & $1810^{3}$ & 2 & 1.25 & 2 \\
\hline
\end{tabular}


Table C.7 gives the values of the model parameters at $1030^{\circ} \mathrm{C}$ and table C.8 the 453 temperature evolution of the microstructural parameters identified for the $\beta$-heat 454 treated titanium alloy.

Table C.7: Temperature model parameters at $1030^{\circ} \mathrm{C}$

\begin{tabular}{|c|c|c|c|c|c|c|c|}
\hline$\sigma^{0}[M P a]$ & $Q[M P a]$ & $b$ & $a\left[s^{-1}\right]$ & $n$ & $E_{\beta}[G P a]$ & $D[M P a]$ & $f_{m a}$ \\
\hline 0 & 1 & 1 & 1.1 & 3 & 35 & 85 & $110^{-1}$ \\
\hline
\end{tabular}

Table C.8: Updated microstructural parameters for the $\beta$-treated Ti-6Al-4V

\begin{tabular}{|c|c|c|c|c|c|c|c|c|c|c|}
\hline$\theta\left[{ }^{\circ} \mathrm{C}\right]$ & 1030 & 950 & 900 & 800 & 700 & 600 & 500 & 400 & 300 & 20 \\
\hline$Z_{\alpha_{I}}$ & \multicolumn{10}{|c|}{0} \\
\hline$Z_{\alpha_{I I}}$ & 0 & 0.22 & 0.44 & \multicolumn{8}{|c|}{0.82} \\
\hline$Z_{\beta}$ & 1 & 0.78 & 0.56 & \multicolumn{8}{|c|}{0.18} \\
\hline$B$ & \multicolumn{10}{|c|}{$80.610^{-3}$} \\
\hline
\end{tabular}




\section{References}

\section{References}

[1] R. Boyer, E. Collings, G. Welsch, Materials Properties Handbook: Titanium Alloys, 4th Edition, ASM International, 2007.

[2] A. Majorell, S. Srivatsa, R. Picu, Mechanical behavior of Ti-6Al-4V at high and moderate temperatures - Part I: Experimental results, Materials Science and Engineering: A 326 (2) (2002) 297-305.

[3] M. Vanderhasten, Ti-6Al-4V: Deformation map and modelisation of tensile behaviour, thése de Doctorat, Katholieke Universiteit Leuven, 2007.

[4] R. Picu, A. Majorell, Mechanical behavior of Ti-6Al-4V at high and moderate temperatures - Part II: constitutive modeling, Materials Science and Engineering: A 326 (2002) 306-316.

[5] B. Cheong, J. Lin, A. Ball, Modelling of hardening due to grain growth for a superplastic alloy, Journal of Materials Processing Technology 119 (2001) 361-365.

[6] S. Semiatin, F. Montheillet, G. Shen, J. Jonas, Self-consistent modeling of the flow behavior of wrought alpha/beta titanium alloys under isothermal and nonisothermal hot-working conditions, Metallurgical and Materials Transactions A 33 (2002) 2719-2727.

[7] Y. Robert, Simulation numérique du soudage du TA6V par laser YAG impulsionnel: caractérisation expérimentale et modélisation des aspects thermomécaniques associés à ce procédé, thèse de Doctorat, École des Mines de Paris, 2007.

[8] Z. Tao, H. Yang, H. Li, X. Fan, Quasi-static tensile behavior of large-diameter thin-walled Ti-6Al-4V tubes at elevated temperature, Chinese Journal of Aeronautics 29 (2) (2016) 542-553.

[9] O. Bouaziz, Revisited storage and dynamic recovery of dislocation density evolution law: Toward a generalized kocks-mecking model of strain-hardening, Advanced Engineering Materials 14 (9) (2012) 759-761.

[10] H. Mecking, B. Nicklas, N. Zarubova, U. Kocks, A universal temperature scale for plastic flow, Acta Metallurgica 34 (3) (1986) 527-535.

[11] J. Lin, T. Dean, Modelling of microstructure evolution in hot forming using unified constitutive equations, Journal of Materials Processing Technology 167 (2005) 354-362.

[12] J. Lin, J. Yang, GA-based multiple objective optimisation for determining viscoplastic constitutive equations for superplastic alloys, International Journal of Plasticity 15 (11) (1999) 1181-1196. 
[13] X. Fan, H. Yang, Internal-state-variable based self-consistent constitutive modeling for hot working of two-phase titanium alloys coupling microstructure evolution, International Journal of Plasticity 27 (11) (2011) 1833-1852.

[14] J. Teixeira, B. Denand, E. Aeby-Gautier, S. Denis, Simulation of coupled temperature, microstructure and internal stresses evolutions during quenching of a $\beta$-metastable titanium alloy, Materials Science and Engineering A 651 (2016) 615-625.

[15] J. Teixeira, B. Denand, E. Aeby-Gautier, S. Denis, Influence of the $\beta \rightarrow \alpha+\beta$ transformation on the stresses and strains evolutions during quenching of the Ti17 alloy from the $\beta$ phase field, in: Thermal Process Modeling: Proceedings from the 5th International Conference on Thermal Process Modeling and Computer Simulation, ASM International, 2014, pp. 199-209.

[16] V. Velay, H. Matsumoto, V. Vidal, A. Chiba, Behavior modeling and microstructural evolutions of Ti-6Al-4V alloy under hot forming conditions, International Journal of Mechanical Sciences 108-109 (2016) 1 - 13.

[17] E. Alabort, P. Kontis, D. Barba, K. Dragnevski, R. Reed, On the mechanisms of superplasticity in Ti-6Al-4V, Acta Materialia 105 (2016) 449 - 463.

[18] A. Laasraoui, J. Jonas, Prediction of steel flow stresses at high temperatures and strain rates, Metallurgical Transactions A 22A (7) (1991) 1545-1558.

[19] H. Mecking, Strain hardening and dynamic recovery, in: Dislocation Modelling of Physical Systems, Pergamon, 1981, pp. 197-211.

[20] A. Momeni, S. Abbasi, M. Morakabati, A. Akhondzadeh, Yield point phenomena in TIMETAL 125 beta Ti alloy, Materials Science and Engineering: A 643 (2015) 142-148.

[21] X. Wang, H. Hamasaki, M. Yamamura, R. Yamauchi, T. Maeda, Y. Shirai, F. Yoshida, Yield-Point Phenomena of Ti-20V-4Al-1Sn at $1073 \mathrm{~K}$ and Its Constitutive Modelling, Materials Transactions 50 (6) (2009) 1576-1578.

[22] X. Wang, H. Hamasaki, M. Yamamura, R. Yamauchi, T. Maeda, Y. Shirai, F. Yoshida, A Study of High Temperature Viscoplastic Deformation of Beta Titanium Alloy Considering Yield-point Phenomena, Key Engineering Materials 410-411 (2009) 177-185.

[23] F. Montheillet, Comportement rhéologique des matériaux métalliques multiphasés, Techniques de l'Ingénieur m3010 (2012) 24.

[24] F. Yoshida, A constitutive model of cyclic plasticity, International Journal of Plasticity 16 (2000) 359-380.

[25] F. Yoshida, Y. Kaneda, S. Yamamoto, A plasticity model describing yield-point phenomena of steels and its application to FE simulation of temper rolling, International Journal of Plasticity 24 (2008) 1792-1818. 
[26] E. Taleff, C. Syn, D. Lesuer, O. Sherby, Pearlite in ultrahigh carbon steels: Heat treatments and mechanical properties, Metallurgical and Materials Transactions A 27 (1) (1996) 111-118.

[27] F. Perdrix, M. Trichet, J. Bonnentien, M. Cornet, J. Bigot, Influence of cooling rate on microstructure and mechanical properties of a Ti-48Al alloy, Intermetallics 7 (12) (1999) 1323-1328.

[28] F. Perdrix, M. Trichet, J. Bonnentien, M. Cornet, J. Bigot, Influence of nitrogen on the microstructure and mechanical properties of Ti-48Al alloy, Intermetallics 9 (2001) 147-155.

[29] H. Ishii, K. Ohkubo, S. Miura, T. Mohri, Mechanical Properties of $\alpha+\kappa$ Twophase Lamellar Structure in Fe-Mn-Al-C Alloy, Materials Transactions 44 (9) (2003) 1679-1681.

[30] R. Julien, V. Velay, V. Vidal, Y. Dahan, R. Forestier, F. Rézaï-Aria, Tensile behaviour of high temperature forged ti-6al-4v during in-situ heat treatments, Materials Letters 208 (Supplement C) (2017) 7 - 9.

[31] I. Katzarov, S. Malinov, W. Sha, Finite Element Modeling of the Morphology of $\beta$ to $\alpha$ Phase Transformation in Ti-6Al-4V Alloy, Metallurgical and Materials Transactions A 33 (4) (2002) 1027-1040.

[32] J. Elmer, T. Palmer, S. Babu, E. Specht, In situ observations of lattice expansion and transformation rates of $\alpha$ and $\beta$ phases in Ti-6Al-4V, Materials Science and Engineering A 391 (1-2) (2005) 104-113.

[33] I. Lonardelli, N. Gey, H.-R. Wenk, M. Humbert, S. Vogel, L. Lutterotti, In situ observation of texture evolution during $\alpha \rightarrow \beta$ and $\beta \rightarrow \alpha$ phase transformations in titanium alloys investigated by neutron diffraction, Acta Materialia 55 (17) (2007) $5718-5727$.

[34] Y. Sui, A. Liu, B. Li, J. Guo, Relationship between Thickness of Lamellar $\alpha+\beta$ Phase and Mechanical Properties of Titanium Alloy, Advanced Materials Research 311-313 (2011) 1916-1919.

[35] F. Gil, M. Ginebra, J. Manero, J. Planell, Formation of $\alpha$-Widmanstätten structure: effects of grain size and cooling rate on the Widmanstätten morphologies and on the mechanical properties in Ti6Al4V alloy, Journal of Alloys and Compounds 329 (2001) 142-152.

[36] A. Cottrell, B. Bilby, Dislocation Theory of Yielding and Strain Ageing of Iron, Proceedings of the Physical Society. Section A 62 (1) (1948) 49-62.

[37] G. Hahn, A model for yielding with special reference to the yield-point phenomena of iron and related BBC metals, Acta Metallurgica 10 (8) (1962) 727-738. 
[38] F. Yoshida, Constitutive modeling of large-strain cyclic plasticity for anisotropic metals, in: Hardening and Damage of Materials under Finite Deformations : Constitutive Modeling and Numerical Implementation, Dortmund, 2012, pp. $1-67$.

[39] D. Hull, D. Bacon, Introduction to Dislocations, 5th Edition, Vol. 36, Elsevier, 2011.

[40] C. Kerisit, R. E. Loge, S. Jacomet, V. Llorca, N. Bozzolo, EBSD coupled to SEM in situ annealing for assessing recrystallization and grain growth mechanisms in pure tantalum, Journal of Microscopy 250 (3) (2013) 189-199.

[41] R. Smallman, A. Ngan, Modern Physical Metallurgy, 8th Edition, Elsevier, 2014.

[42] V. Joshi, Titanium Alloys: An Atlas of Structures and Fracture Features, CRC Taylor \& Francis, 2006.

[43] M. Brandes, M. Baughman, M. Mills, J. Williams, The effect of oxygen and stress state on the yield behavior of commercially pure titanium, Materials Science and Engineering A 551 (2012) 13-18.

[44] V. Vidal, Y. Balcaen, F. Pettinari-Sturmel, J. Douin, P. Lours, V. Velay, L. Robert, Experimental Study of the Deformation Mechanisms in Textured Alpha-titanium Alloy Sheets, in: Zhou, L and Chang, $\mathrm{H}$ and Lu, Y and $\mathrm{Xu}, \mathrm{D}$ (Ed.), Ti-2011: Proceedings of the $12^{t h}$ world conference on Titanium, Vol. II, 2012, pp. 1290-1293.

[45] S. Fréour, D. Gloaguen, M. François, R. Guillén, Application of inverse models and XRD analysis to the determination of Ti- $17 \beta$-phase coefficients of thermal expansion, Scripta Materialia 54 (2006) 1475-1478.

[46] B. Bourouga, J. Gilles, Roles of heat transfer modes on transient cooling by quenching process, International Journal of Material Forming 3 (2) (2010) 7788.

[47] Y. Duan, P. Li, K. Xue, Q. Zhang, X. Wang, Flow behavior and microstructure evolution of TB8 alloy during hot deformation process, Transactions of Nonferrous Metals Society of China 17 (6) (2007) 1199 - 1204.

[48] L. Li, Y. Lou, L. Yang, D. Peng, K. Rao, Flow stress behavior and deformation characteristics of Ti-3Al-5V-5Mo compressed at elevated temperatures, Materials and Design 23 (5) (2002) $451-457$.

[49] S. Semiatin, T. Bieler, The effect of alpha platelet thickness on plastic flow during hot working of Ti-6Al-4V with a transformed microstructure, Acta Materialia 49 (17) (2001) $3565-3573$. 